\title{
Ground stone technology in context: Consumption of grinding tools and social practice at Neolithic Avgi, NW Greece
}

\author{
Tasos Bekiaris \\ Department of Archaeology, Aristotle University of Thessaloniki. Greece. Email: anasbek3@gmail.com
}

\begin{abstract}
:
Excavations at the Neolithic site of Avgi (Middle-Late Neolithic, circa 5700-4500 cal. BCE) in the Kastoria region, northwestern Greece, brought to light one of the largest ground stone assemblages known from Neolithic Greece. More than 8000 ground stone tools and objects, raw materials and byproducts comprise a valuable record for investigating various aspects of ground stone technology (production, consumption, discard), while their rich contextual information provides an ideal opportunity for addressing its significance for Neolithic societies.

This paper examines the presence of grinding tools (stable grinding slabs and mobile grinders, their raw materials and by-products) within different spatiotemporal contexts (habitational phases, buildings, open areas, pits). Through the detailed technological and contextual analysis of the grinding artifacts we seek to explore different aspects of their biographies, related to their manufacture, use, maintenance, destruction and discard, within the context of a single Neolithic community. The goal is to shed light on the multiple ways through which the Neolithic society of Avgi consumed those technological products in various social occasions, practices and places (e.g., daily routine activities, special events of communal or symbolic character, individual houses and communal activity areas) and explore their role in the formation of social identities and the production of social meaning.
\end{abstract}

Keywords: ground stone technology; grinding slabs; grinders; contextual analysis; Neolithic Greece

\section{Introduction}

Within the discipline of archaeology, ground stone technology has been strongly associated with plant exploitation and specifically with the transformation of plants into edible substances. Especially in the Old World, grinding tools were perceived as the 'hallmarks' of the Neolithic mode of production and were linked to the emergence of the first farming communities (see discussions in Dubreuil 2008; Hodder 2017; Wright 1994; 2000). Despite their crucial role for understanding prehistoric subsistence and various other aspects of prehistoric life (see Rowan \& Ebeling 2008), grinding tools, such as grinding slabs and

Published by the School of History, Classics and Archaeology, University of Edinburgh ISSN: 2055-0472. URL: http://journals.ed.ac.uk/lithicstudies/

Except where otherwise noted, this work is licensed under a CC BY 4.0 licence. 
grinders were treated by archaeologists in many parts of the world as 'static', indifferent implements, while attempts to approach their social meaning were extremely rare.

The last fifteen years, however, witnessed a global resurgence of ground stone research. Ground stone objects are now perceived as vital material elements of Neolithic life, while current research is moving towards discussions that investigate the social role of these artefacts (Van Gijn 2014; Hamon 2008; Lidström Holmberg 2004; 2008; Rosenberg 2013; Stroulia \& Chondrou 2013; Tsoraki 2007; 2008; 2011; Wright 2014; Wright et al. 2013).

In northern Greece, recent, large-scale excavations on many Neolithic sites, mostly settlements (e.g., Makriyalos: Pappa (2008); Avgi: Stratouli (2013); Kleitos: Ziota (2014); Kremasti: Hondroyianni-Metoki (2010); Koromilia: Stratouli et al. (2014a)) have yielded rich ground stone datasets, counting hundreds of artifacts. The ongoing, systematic study of these assemblages aims at creating new pathways on the analysis and interpretation of ground stone technological products (Bekiaris 2016; 2018: 394-410; Bekiaris et al. 2017; Stroulia 2010b; Stroulia et al. 2017; Tsoraki 2008). Beyond the unquestionable importance of the freshly emerged material data there was another aspect, which had certainly defined the 'new era' of ground stone studies in northern Greece: the vast majority of these finds derive from stratified deposits with well documented contextual information. Thus now, we can pinpoint the exact findspots of the ground stone implements, investigate their temporal distribution, correlate them with stratigraphic sequences and discuss their spatial relation with other artefacts through a microscale perspective. Therefore, we are able to put ground stone technology in context and investigate the varied meaning of these implements within different forms of social practice.

This paper investigates the distribution of grinding tools within different spatiotemporal contexts (habitational phases, buildings, open areas, pits). Through the contextual analysis of the grinding artifacts we seek to explore different aspects of their biographies, related to their manufacture, use, maintenance, destruction and discard, within the context the Neolithic community of Avgi.

\section{The Neolithic site of Avgi \& the ground stone assemblage}

The Neolithic site of Avgi was established on the gentle slopes of a hilly terrain (circa $740 \mathrm{~m}$. above sea level) at Kastoria Region, in northwestern Greece (Figure 1). It represents an extended settlement, exhibiting clear patterns of horizontal habitation shifting. The total extent of the site is estimated at approximately 5 ha. About $2000 \mathrm{~m}^{2}$ have been investigated during excavations carried out from 2002 to 2008 by the Hellenic Ministry of Culture (Stratouli 2005; 2007; 2013). The excavations revealed domestic features, such as houses, thermal structures, open-air activity areas, ditches, pits, but also a group of cremation burials, as well as vast amounts of botanical and faunal remains, pottery, tools, ornaments, miniature clay objects (Stratouli 2013; Stratouli \& Bekiaris 2008; Stratouli et al. 2010; 2011). Three occupation phases, spanning throughout the Middle to the Late Neolithic are evident in the site's stratigraphic sequence: AVGI I, dated to the late Middle Neolithic-early Late Neolithic (circa 5700-5300 to 5200 cal. BCE), AVGI II, dated to Late Neolithic I (circa 5300 to 52004900 cal. BCE) and AVGI III, dated to Late Neolithic II \& III (circa 4900-4500 cal. BCE). The archaeological phases and the chronology follows the periodization proposed in Andreou et al. (2001: tab. 1). The occupation phases and their characteristics will be thoroughly discussed below.

Excavations at Neolithic Avgi brought to light one of the largest ground stone assemblages known from Neolithic Greece. The assemblage comprises circa 8000 ground stone artifacts, among which several tools, other stone objects (e.g., maceheads, stone vases), raw materials and debitage. Large ground stone assemblages are also known from other 
Neolithic sites in northern Greece, such as the recently excavated site at Koromilia at Kastoria (Bekiaris 2016) the sites of Kleitos (Chondrou et al. 2018), Toumba Kremasti Koilada in Kozani (Stroulia et al. 2017) and Makriyalos in Pieria (Tsoraki 2008). The study of Neolithic Avgi's ground stone assemblage begun in 2011 and it is still ongoing. It has so far focused on the macroscopic analysis of 2907 ground stone objects (Bekiaris 2018: 73-75; Bekiaris et al. 2017), deriving from undisturbed Neolithic layers. About 5000 ground stone objects are yet to be studied. These items lack contextual information since they were located in the site's heavily eroded topsoil layer. Based on their technological attributes and use-wear patterns the ground stones of Neolithic Avgi have been assorted to the following categories (Table 1): grinding and abrasive tools, such as stable and handheld grinding stones, polishers and abraders, percussion tools, such as globular hammer stones and tools used in a percussive mode with their ends, edge tools, such as axes, adzes and chisels, multiple-use tools, that could have acted in an abrasive and percussive mode simultaneously, raw materials and debitage, such as ground stone flakes and preforms, miscellanea, including fragments of stone vases, maceheads, stone slabs and pigments, and several objects of undetermined function.

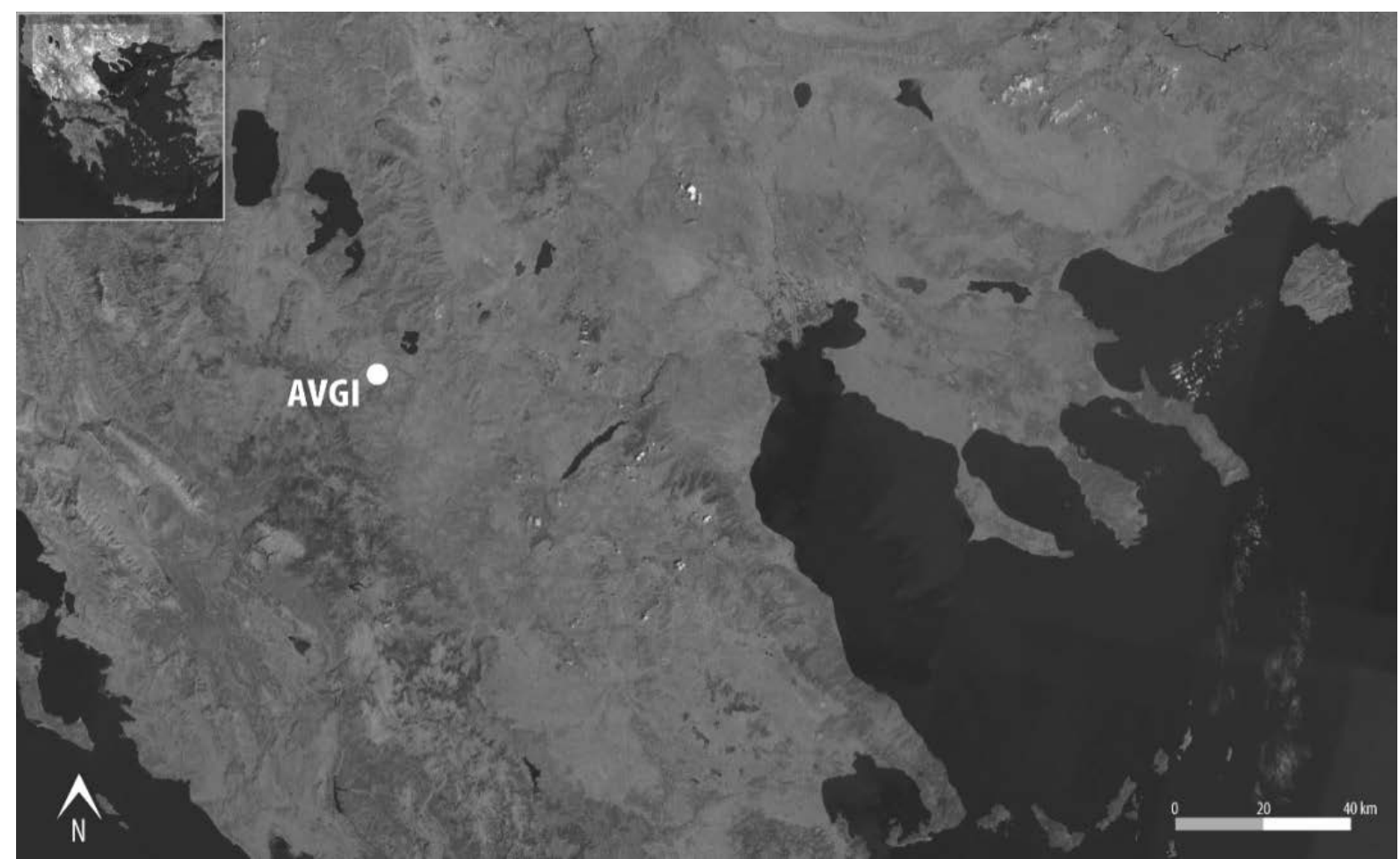

Figure 1. Map of northern Greece showing the location of Avgi.

Table 1. Ground stone categories from Neolithic Avgi and their frequencies.

\begin{tabular}{lcc}
\hline Ground stone category & Number & Percent \% \\
\hline Grinding and abrasive tools & 2075 & $71.4 \%$ \\
Miscellaneous objects & 183 & $6.3 \%$ \\
Edge tools & 176 & $6.1 \%$ \\
Raw materials \& debitage & 153 & $5.3 \%$ \\
Multiple use tools & 119 & $4.1 \%$ \\
Percussion tools & 105 & $3.6 \%$ \\
Indeterminate tools & 96 & $3.3 \%$ \\
\hline Total & $\mathbf{2 9 0 7}$ & $\mathbf{1 0 0 \%}$ \\
\hline
\end{tabular}


This paper focuses on 704 grinding tools (Table 2) deriving from various contexts, such as houses, open areas and pits, of all three occupation phases (AVGI I, II and III). Some of these tools $(n=117)$ could have acted as static grinding slabs, while most of them $(n=473)$ served as handheld, mobile grinders. Both tool-types could have worked in combination with each other, forming the well-known technological sets of grinding equipment, or even independently for various processing activities (the processing of foodstuffs, pigments, minerals or the manufacture of objects). For some artifacts $(n=114)$ it is unclear whether they have been used in a static or mobile mode (grinding implements of undetermined function).

Table 2. Grinding tools frequencies and their distribution to the habitation phases.

\begin{tabular}{lcccccccccc} 
& \multicolumn{2}{c}{ AVGI I } & \multicolumn{2}{c}{ AVGI II } & \multicolumn{2}{c}{ AVGI III } & \multicolumn{2}{c}{ AVGI ? } & \multicolumn{2}{c}{ Total } \\
Grinding tools & $\mathbf{N}$ & $\mathbf{\%}$ & $\mathbf{N}$ & $\mathbf{\%}$ & $\mathbf{N}$ & $\mathbf{\%}$ & $\mathbf{N}$ & $\mathbf{\%}$ & $\mathbf{N}$ & $\mathbf{\%}$ \\
\hline Grinding slab & 43 & $18.8 \%$ & 37 & $14.9 \%$ & 26 & $19 \%$ & 11 & $12.4 \%$ & 117 & $16.6 \%$ \\
$\begin{array}{l}\text { Undetermined } \\
\text { grinding tool }\end{array}$ & 48 & $21.0 \%$ & 36 & $14.5 \%$ & 13 & $9.5 \%$ & 17 & $19,1 \%$ & 114 & $16.2 \%$ \\
Grinder & 138 & $60.3 \%$ & 176 & $70.7 \%$ & 98 & $71.5 \%$ & 61 & $68.5 \%$ & 473 & $67.2 \%$ \\
\hline Total & $\mathbf{2 2 9}$ & $\mathbf{1 0 0 \%}$ & $\mathbf{2 4 9}$ & $\mathbf{1 0 0 \%}$ & $\mathbf{1 3 7}$ & $\mathbf{1 0 0 \%}$ & $\mathbf{8 9}$ & $\mathbf{1 0 0 , 0 \%}$ & $\mathbf{7 0 4}$ & $\mathbf{1 0 0 \%}$ \\
\hline
\end{tabular}

\section{The technology of grinding tools: rocks, manufacture, morphology and use}

In Neolithic Avgi various types of locally available rocks, such as sandstones, conglomerates, granites and gneisses, were chosen for the production of the grinding tools. The selection process was strongly affected by the mechanical properties of the rocks and their functional suitability for the intended tasks (see Bekiaris et al. 2017). The presence of waterworn surfaces on the unutilized parts of the tools (sides, bases) suggest that the vast majority of these rocks were collected from local secondary sources, such as the riverbed and banks of Aliakmonas River and its tributaries. The acquired rocks were transformed into functional grinding implements with the application of two percussive manufacturing techniques: flaking and pecking. In the case of grinding slabs (Figure 2) and some large grinders (Figure 3) it is clear that these techniques were employed by the necessity to create a broad, mostly even and rough workface over the curved and smooth surfaces of the watertransported raw materials (see Stroulia 2010a). Flaking was probably used at the initial modification stages in order to form and roughen the tool's active face, while pecking was applied in order to finalize the surface and create the proper configuration and necessary roughness. Pecking was also used for the rejuvenation of the active surfaces when they became dull from the prolonged or intense abrasive use. Not all the grinding implements were the outcome of formalised production sequences. Most of the small-sized handstones (Figure 4) represent rocks that have been modified exclusively through use (a posteriori tools, Stroulia 2010a). However, some of them had received pecking in order to roughen their smooth faces. The production of some grinding tools was probably local and had occurred mostly on site, as suggested by the presence of unworked raw materials, primary and secondary flakes and few unused tools (see Bekiaris 2018: 396-399). 

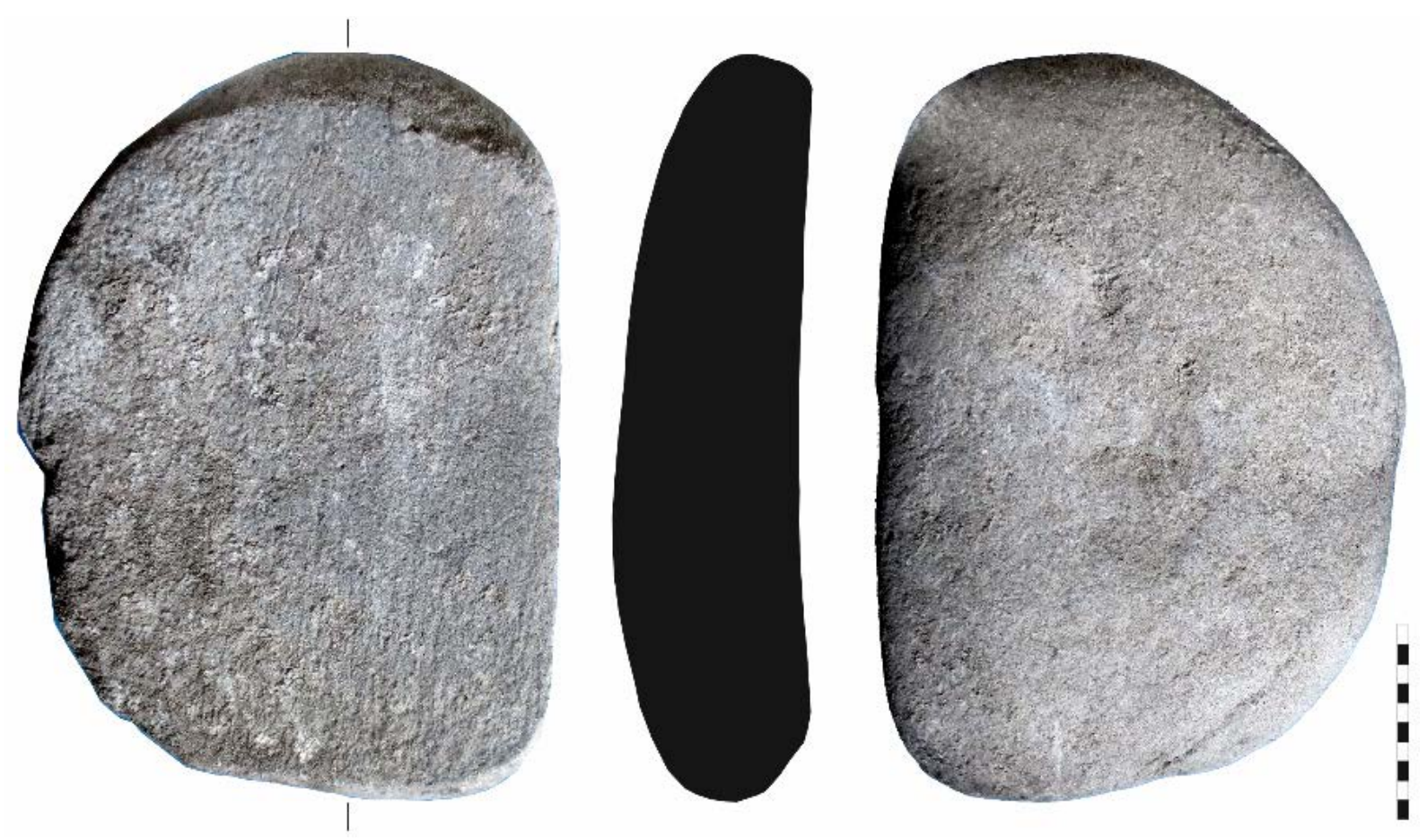

Figure 2. Grinding slab: workface, length section and base (scale in cm).
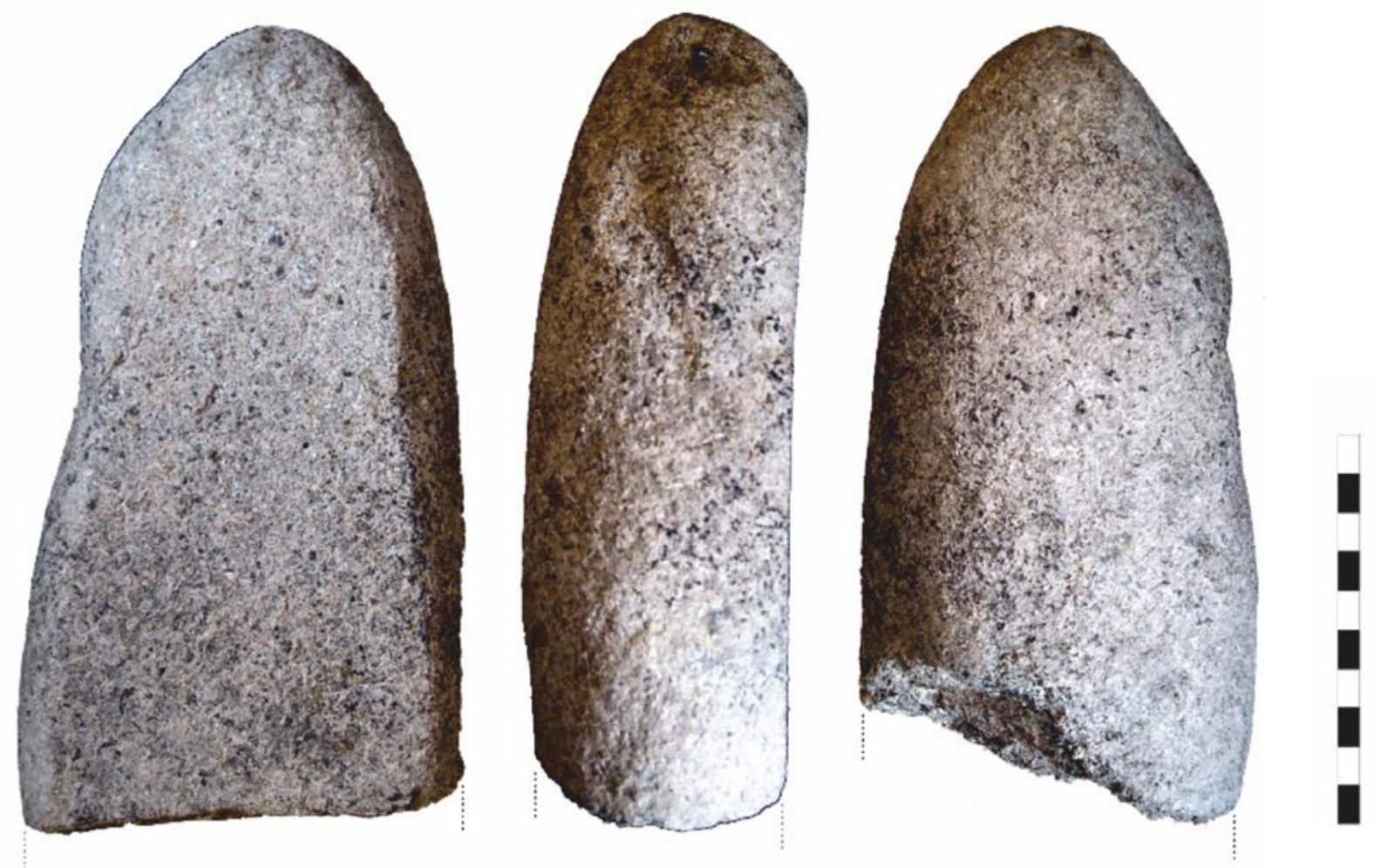

Figure 3. Grinder: workface, profile and dorsal face (scale in cm). 

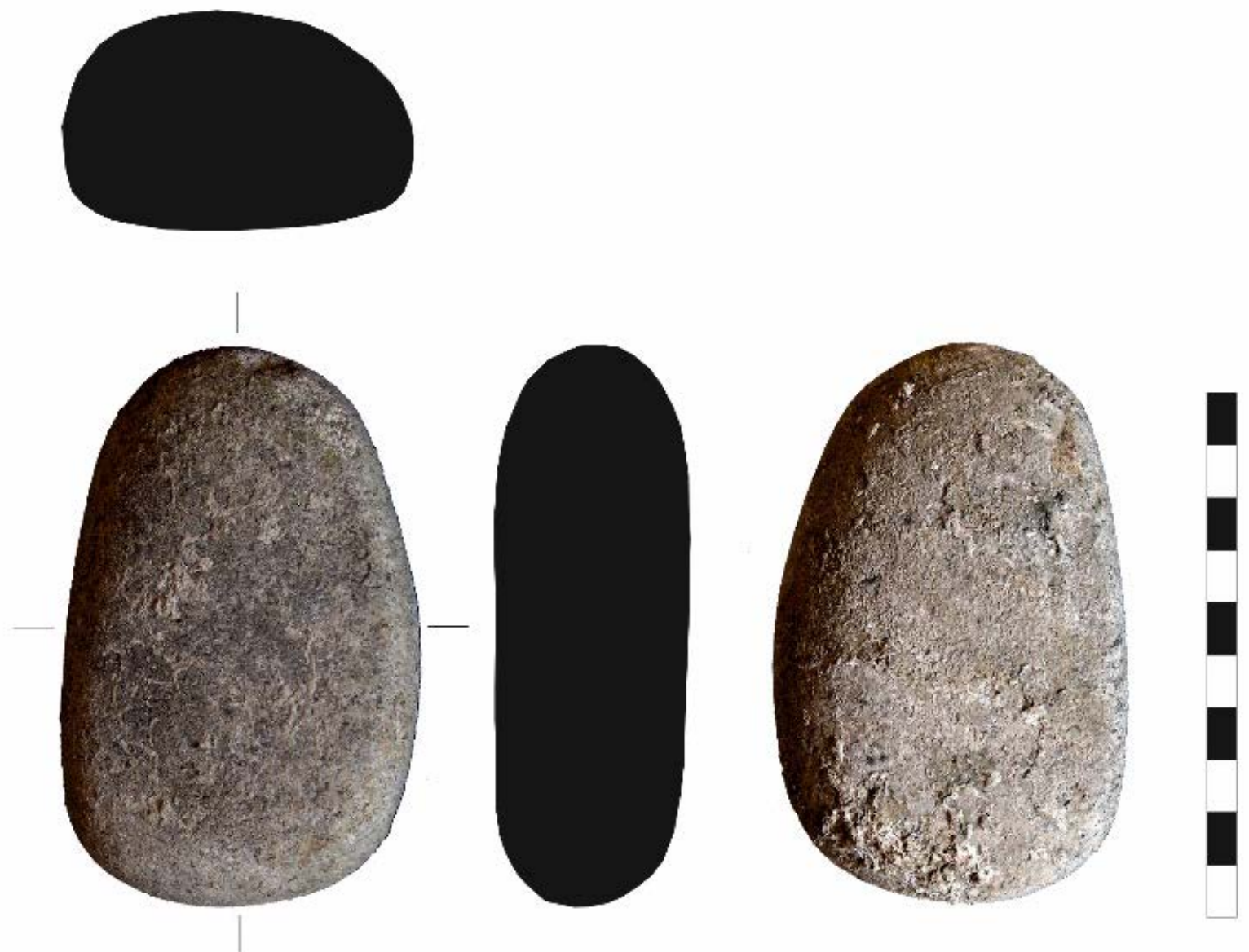

Figure 4. Handstone: workfaces, length and width sections (scale in $\mathrm{cm}$ ).

The size of the Avgi grinding slabs is quite large as can be inferred from the few intact specimens and their comparison with the fragmented cases. Their average length ranges between 30.0 to $39.0 \mathrm{~cm}$, their width between 13.0 to $30.0 \mathrm{~cm}$ and their thickness between 5.00 to $9.00 \mathrm{~cm}$. The maximum values for their length, width and thickness are 46.0, 36.0 and $14.0 \mathrm{~cm}$ respectively. These sizes appear to be suitable for tasks such as cereal grinding, since the tools are large enough to hold adequate amounts of processed foodstuffs (see Stroulia 2010a). The dimensions of grinders are extremely variable: their lengths indicate tools small enough (Figure 4) to be held with one hand (length values between 5.00 to $15.00 \mathrm{~cm}$ ) and also large and heavy implements (Figure 3) that would have required the use of both hands in order to be manipulated (length values between 15.00 to $32.00 \mathrm{~cm}$ ). The two-hand grinders are almost identical to the grinding slabs in terms of raw materials, manufacture and maintenance techniques, workface configuration and sizes. Most of them were classified as 'active implements' because of their oblong shape and narrow width which rarely exceeds the $13 \mathrm{~cm}$. Grinders of similar sizes are rarely reported from Greek Neolithic sites. Some exceptions, however, are known from the Cave of Alepotrypa at Diros, Southern Greece (Stroulia 2018), the site of Koromilia in Kastoria (Bekiaris 2016), the site of Kremasti in Kozani (Stroulia et al. 2017) and the site of Iliotopos in Central Macedonia (Chadou 2011: 80).

Grinding slabs from Neolithic Avgi tend to have an elliptical or sub-rectangular plan shape, while grinders exhibit a greater morphological variability with elliptical, rectangular, circular, cylindrical, conical, triangular and trapezoid plan shapes. Most of these shapes reflect the natural forms of the chosen waterworn raw materials. 
The grinding tools from Neolithic Avgi were consumed in multiple and complex ways, as can be inferred from the study of their workfaces and the macroscopic analysis of their usewear (Bekiaris 2018: 226-255). Grinding slabs tend to have only one usually broad, open and mostly flat workface and rarely two opposite ones. During their use-lives the originally flattish workfaces have developed multiple configurations (flat and flat, concave and flat, concave and concave, concave and convex) across their longitudinal and transverse axis, as a result of the contact surface, the kinetics employed and generally the mode of use. Very few specimens bear a concave workface that would have restricted the substances during processing (Figure 5). These tools derive mostly from the upper habitation phases (AVGI II \& III) and may reflect a technological change in the grinding equipment of the Neolithic community. The workfaces of the grinding tools exhibit various combinations of abrasive use wear, such as levelling and smoothing, grain extraction, linear traces and sheen. Some of them could have resulted from different use episodes and modes of use, as suggested by the presence of overlapping wear traces and use surfaces. The handheld tools have been used with one or two workfaces, exhibiting similar configurations and use wear occurrences with the grinding slabs. Some of the active tools have been also used with their ends and sides in an abrasive or percussive manner. The flexible character of the grinding tools is further documented by the practices recycling and redesigning (see Stroulia 2010a: 7), which are encountered rather often in the material from Neolithic Avgi. Prior to their recycling, some grinding slabs have been redesigned through a percussive technique, such as flaking, in order to be used as grinders (Figure 6). Other grinding implements have been recycled after their breakage as abraders without the need of any other modification. Some active tools were also recycled as pounders or hammers (Figure 7).

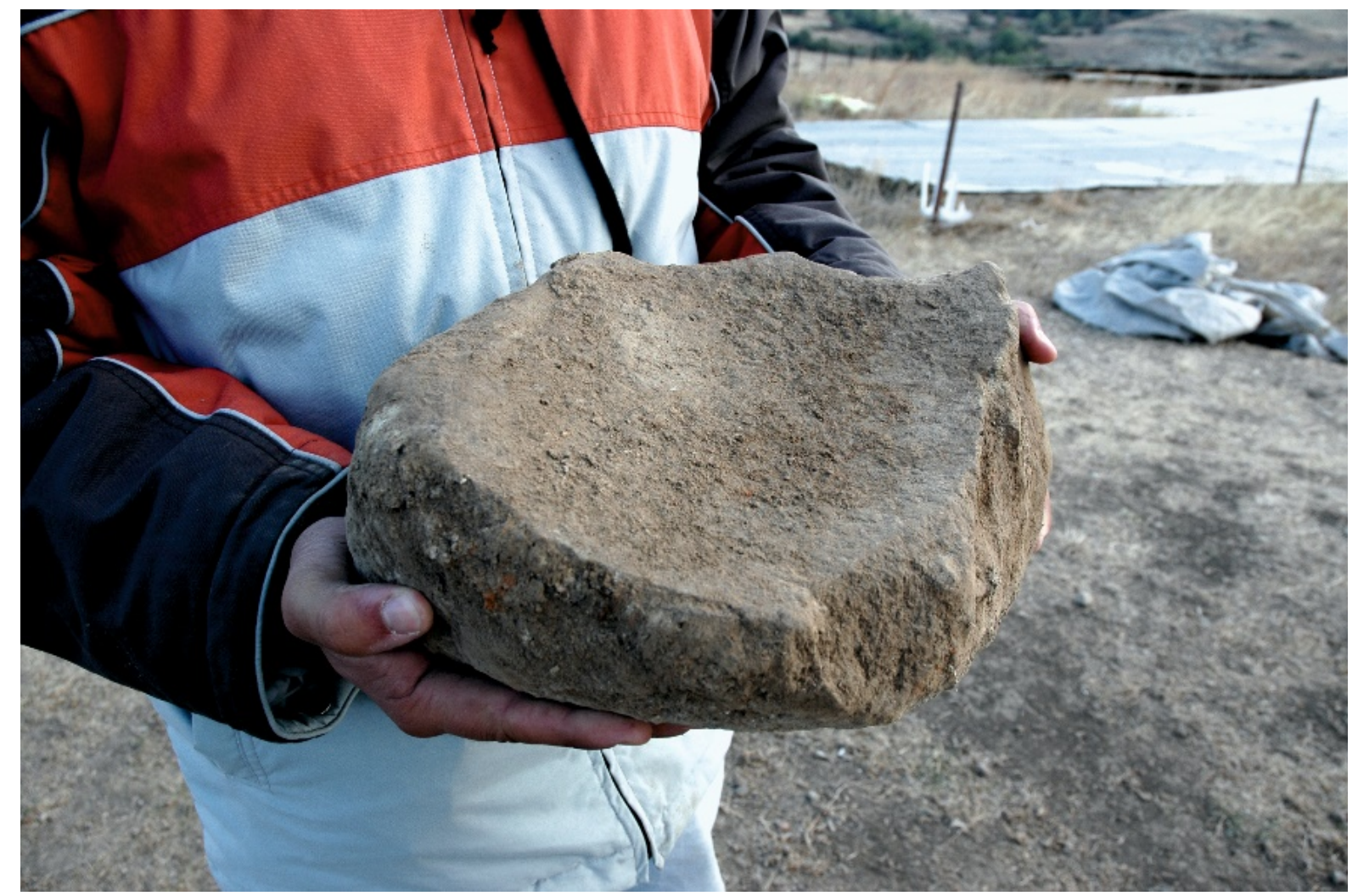

Figure 5. Grinding slab with a concavity from an AVGI III pit. 

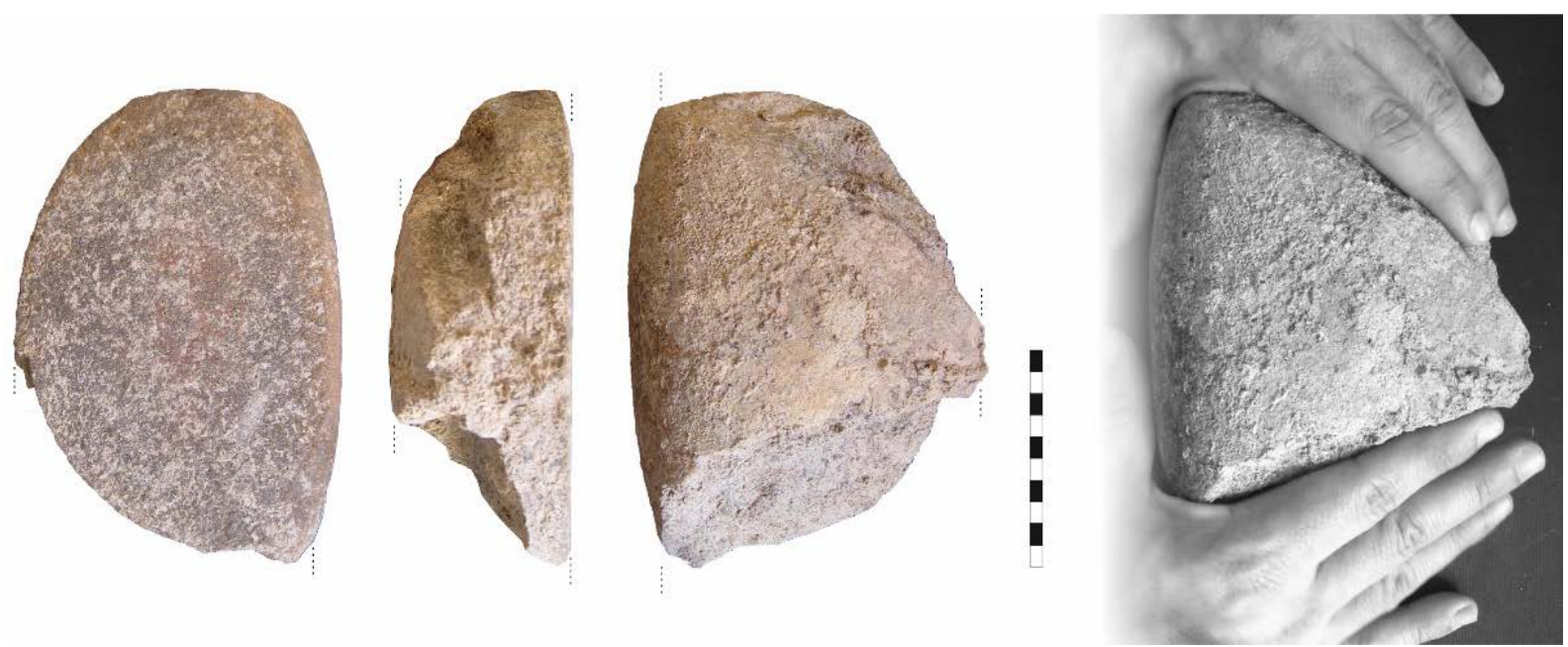

Figure 6. Grinding slab redesigned through flaking in order to be used as a grinder. Workface, profile, dorsal face and suggested way of holding (scale in $\mathrm{cm}$ ).
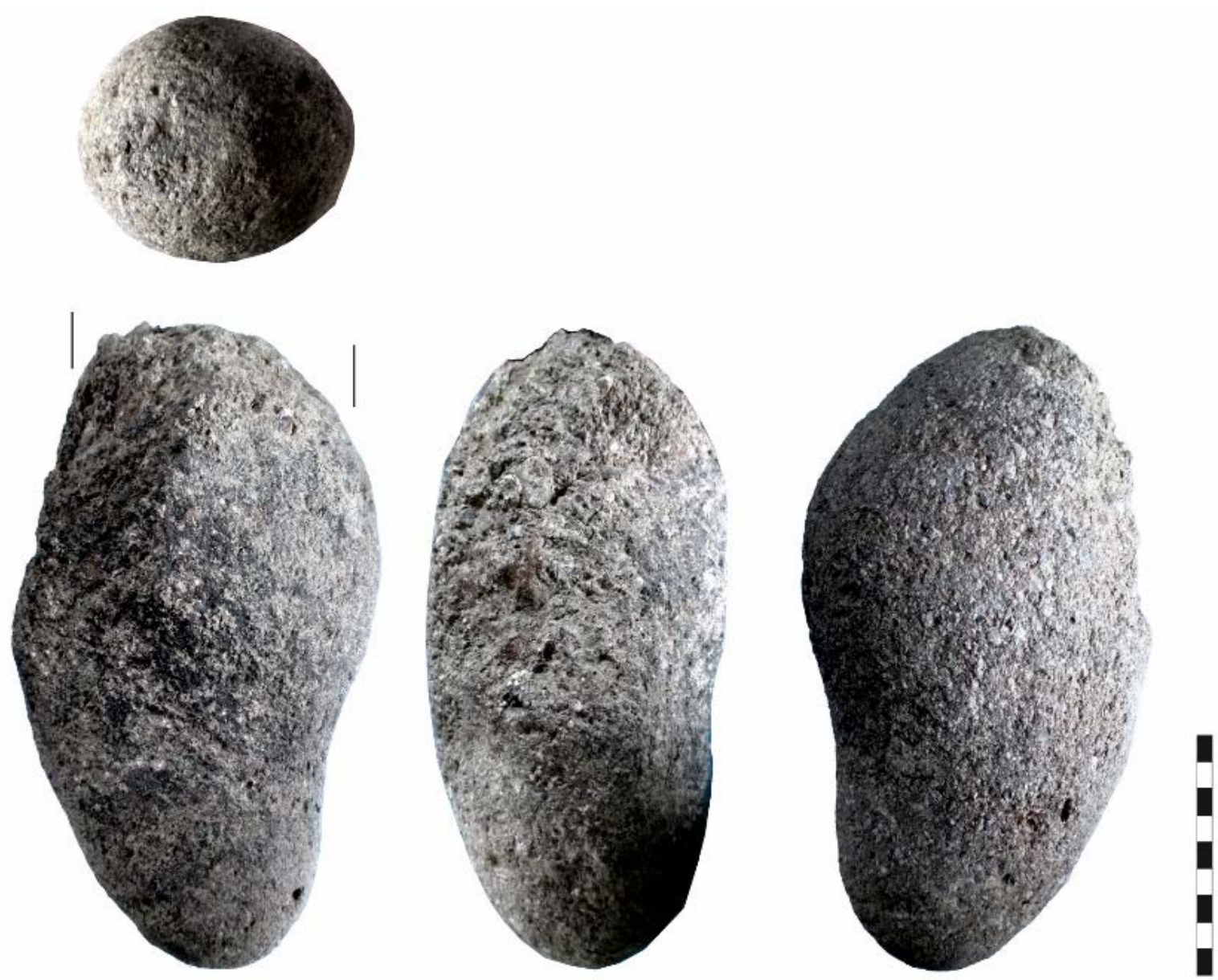

Figure 7. Grinder redesigned through flaking in order to be used as a pounder. Active end (top) and various faces (scale in $\mathrm{cm}$ ).

The breakage of the grinding tools from Neolithic Avgi seems to be a rather crucial point at their biographies. The vast majority of grinding implements survive at an extremely fragmented state (less than the $25 \%$ of the original tool), while intact implements are extremely rare (18 out of 117 grinding slabs, 78 out of 471 grinders and 1 out of 114 grinding slabs or grinders). Given that most tools derive from deposits which were not affected by modern ploughing, the high degree of fragmentation seems rather peculiar and can be 
interpreted as the choice of consuming these technological products with specific ways. Exhaustion, intense redesigning and prolonged recycling are aspects that certainly had a great impact on those tools, in terms of weakening them and thus making them more vulnerable to accidental breaks (e.g., breaking from the applied pressure or friction during the abrasion process, breaking during pecking). Besides those practices the grinding tools from Neolithic Avgi often bear evidence of deliberate breakage (Adams 2008) as was indicated by the careful examination of their fractures, the presence of the impact points (Figure 8) and the recognition of specific breakage patterns (e.g., systematic and intense breakage, multidirectional breakage, conchoidal breakage, geometric breakage). This evidence exceeds the scope of this paper; the social connotations of such practices are thoroughly discussed in Bekiaris (2018: 308-324).
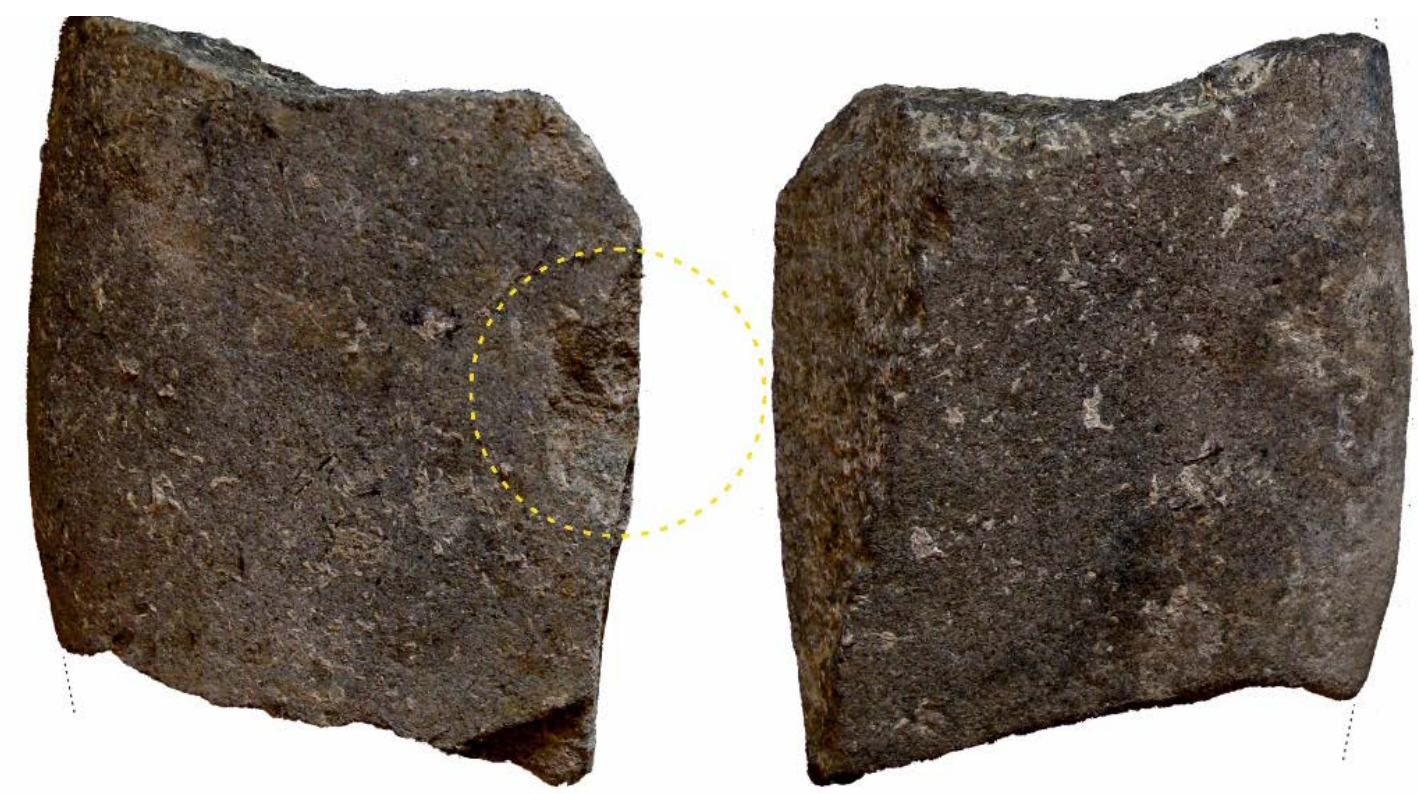

Figure 8. Grinding slab fragment with visible impact point (indicated with a circle). Workface and dorsal face (scale in $\mathrm{cm}$ ).

\section{The contexts of grinding tools: places of production, consumption and discard}

\subsection{AVGI I: Houses and open areas}

AVGI I is the earliest occupation phase, dating to the Middle and Late Neolithic. Its deposits lay directly on the natural alluvial clay bed and are characterized by the remains of above ground, rectangular buildings (Stratouli 2013; Stratouli \& Bekiaris 2008; Stratouli et al. 2011), which were destroyed by fire. Their superstructures have collapsed upon active or recently abandoned use surfaces, thus sealing and protecting their contents from postdepositional disturbance. Based on their finds the AVGI I buildings are considered to represent houses (Stratouli 2013). In between them, extended open areas have been excavated (Figure 9). These areas yielded several thermal structures (their presence inside the buildings is rather vague, see Kalogiropoulou 2013: 105; Stratouli et al. 2011), like ovens and hearths, thousands of tools and objects, as well as great amounts of food and other organic remains (Stratouli et al. 2011). The variety and the large quantities of the finds indicate that open areas had once been bustling places for the social life of the Neolithic community at Avgi, hosting a great variety of daily activities (object production and repair, cooking, food processing or discard) and social interactions (Kalogiropoulou 2013: 132-136). 


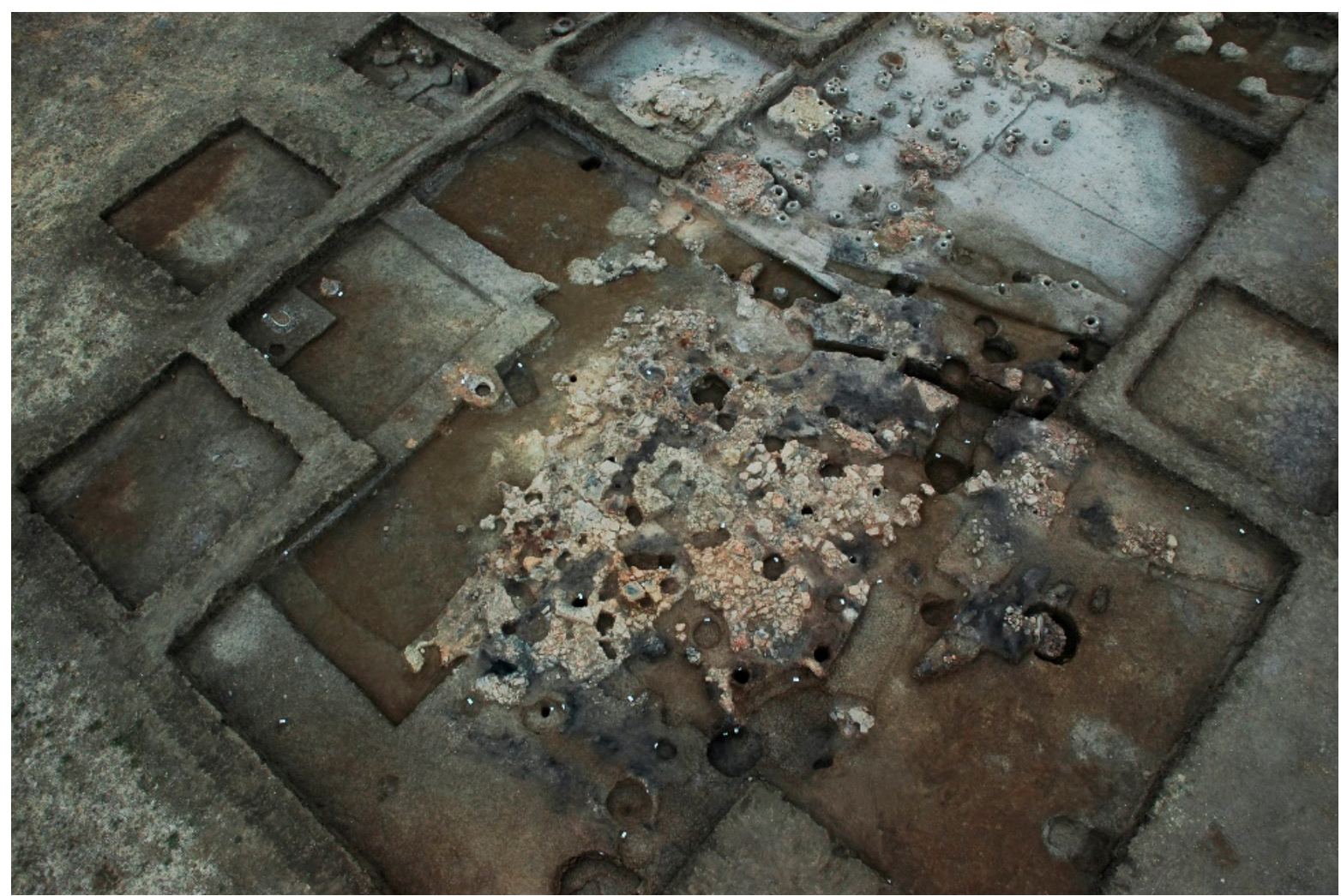

Figure 9. AVGI I: Building 5 and the neighboring open areas.

Five AVGI I buildings have so far been excavated: Buildings 1, 2a, 3, 5 and 7. Their deposits yielded 109 ground stone artifacts in total, among which 41 grinding implements: 7 grinding slabs, 25 grinders and 9 grinding tools of undetermined function (see their distribution in Table 3). Some of them have been found enfolded in the burnt daub remains of the buildings, destroyed and totally deformed by the intense fire. A few specimens, mostly grinding slabs, have been uncovered in situ on the buildings' floors. In the case of Building 2a a large grinding slab (Figures 10 \& 11) was found along with a storage or cooking clay vessel and small concentrations of agricultural products (Triticum dicoccum and Lathyrus sativuscicera). According to Margaritis (2007) these products were found at an already processed state, with their hulls removed, while some of them have been also submitted to pounding or coarse grinding and may represent foodstuffs in the form of bulgur (Margaritis 2007). Similar finds are also known from other AVGI I buildings (such as Buildings 1 and 5) suggesting that some form of short term food storage and maybe processing and cooking were organized by the household and could have occurred inside the house. Common attributes in the technical features and raw materials of the grinding tools (e.g., their modest sizes, the preference of granites and sandstones, the configuration and treatment of the workfaces) suggest that the Neolithic households of AVGI I shared common concepts about the manufacture and curation of these tools and that they had access to the same material sources (see also Tsoraki 2008). However, no evidence of manufacture or treatment of grinding tools derives from the houses. Even if the household was responsible for making and curating its grinding equipment it is highly possible that such actions took place outdoors as the evidence suggest (see below) or that their waste products have been regularly removed from the interior of the houses in order to keep them clean (for an ethnographic example see Searcy 2011). 
Table 3. Frequencies of grinding tools within the AVGI I houses. Differences in the quantities of grinding tools are the result of the different degree of excavation of each house.

\begin{tabular}{lccccccc}
\hline Grinding tools & Building 1 & Building 2a & Building 3 & Building 5 & Building 7 & Total \\
\hline Grinding slab & 3 & 1 & 0 & 2 & 1 & 7 \\
Undetermined & 1 & 0 & 0 & 3 & 5 & 9 \\
Grinder & 5 & 0 & 1 & 6 & 13 & 25 \\
\hline Grand Total & $\mathbf{9}$ & $\mathbf{1}$ & $\mathbf{1}$ & $\mathbf{1 1}$ & $\mathbf{1 9}$ & $\mathbf{4 1}$ \\
\hline
\end{tabular}

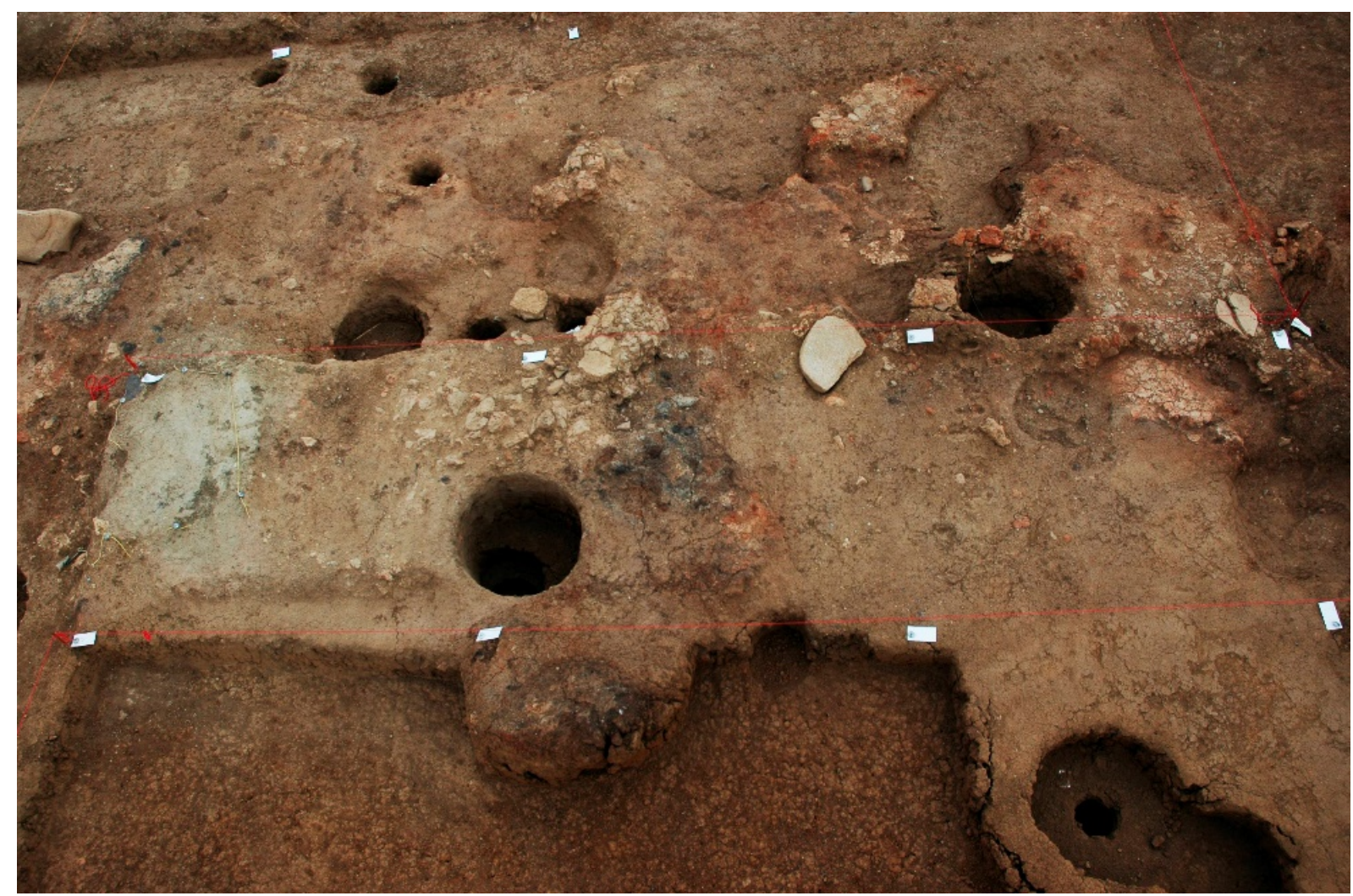

Figure 10. Grinding slab resting on the floor of Building 2a (AVGI I).

Contrary to the houses, the AVGI I open areas have yielded a tremendous amount of ground stone tools ( $\mathrm{n}=622)$, among which are 118 grinding implements, 36 grinding slabs, 113 grinders and 39 grinding tools of undetermined function. The vast majority of the grinding implements derive from open areas located at the north of Building 5 (henceforth Area N5). Area N5 is characterized by the presence of several in situ thermal structures, exhibiting various typological and functional attributes, indicative of equipment that could have supported different forms of cooking, like boiling, roasting, grilling and parching (see Kalogiropoulou 2013: 110). These open air kitchen locales were probably used on a daily basis by the inhabitants of the nearby households (Building 5 and 2a), perhaps sharing the food preparation equipment and -at some occasions- the produced meals (Stratouli et al. 2011). Grinding tools are intriguingly absent from the immediate vicinity of the open air cooking facilities. It seems that the areas around the thermal structures were meant to be kept clean in order to ensure their functionality and ease the movement of their users. On the contrary, grinding tools occur at the periphery of the kitchen spaces, at distances of circa 3-5 $\mathrm{m}$., suggesting that in the AVGI I occupation phase food processing and cooking areas were located very close but they were not spatially identical (Stratouli et al. 2013). A possible open air grinding locale was located in Area N5, where a group of 8 intact grinding slabs and grinders have been unearthed (Figure 12). All tools were made of coarse-grained sandstones, 
while similarities in their use-wear and workface configurations (e.g., grinding slabs slightly concave on both axes) could indicate that they have been used in a similar manner, perhaps in the context of the same activity. The small number of the tools suggests that this equipment was used to process small amounts of food or other substances, perhaps in order to support the needs of small social units or individual households. Other parts of Area N5 have yielded mostly broken and destroyed grinding tools.
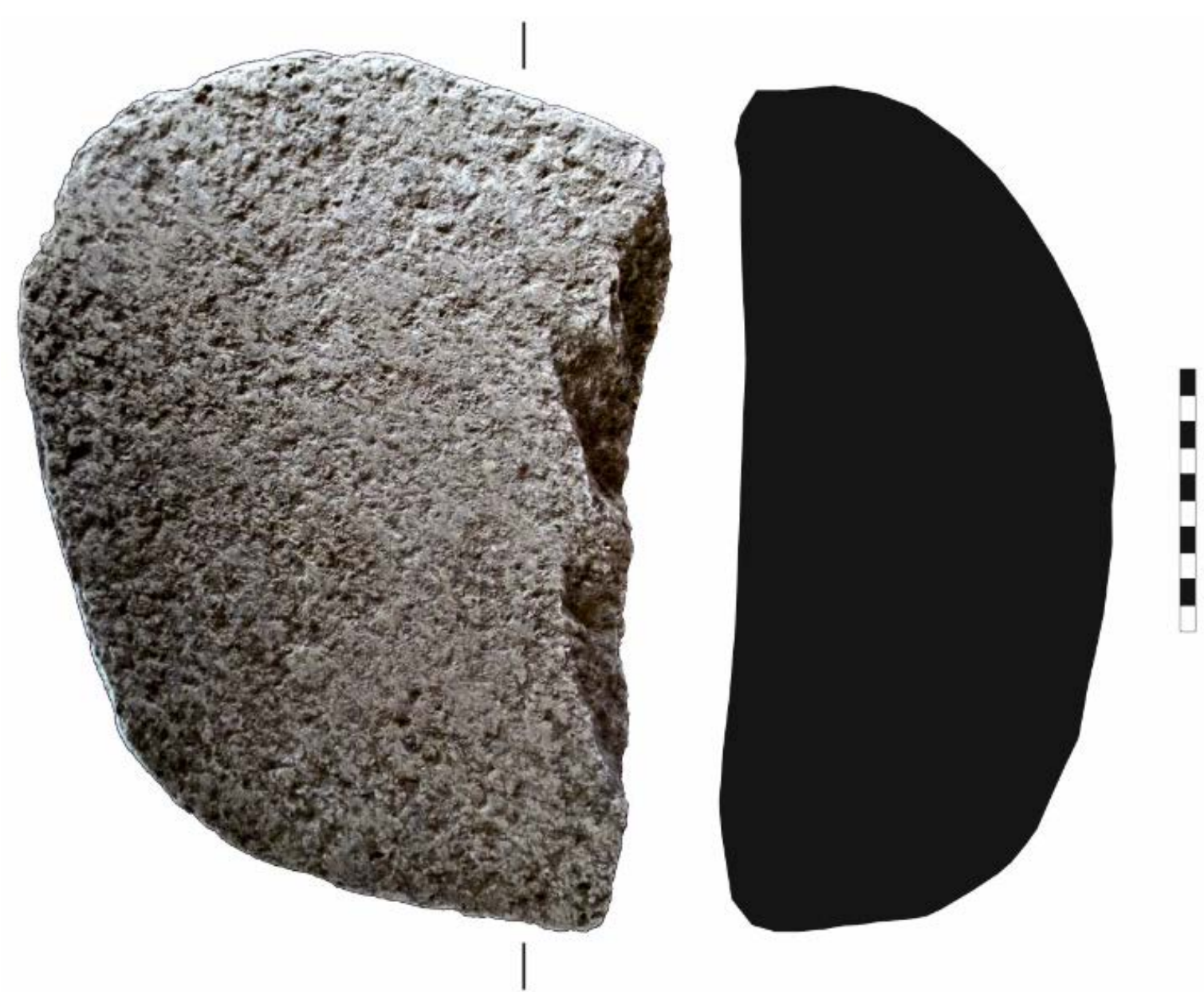

Figure 11. The grinding slab from Building 2a (AVGI I). Workface and width section (scale in cm).

These implements survive in a very fragmentary state. Equally poor is the preservation of their workfaces, which are either worn out or destroyed (burnt, broken or recycled). These tools were probably discarded in those areas after the end of their use lives. They are usually found among other refuse materials, such as animal bones, pottery fragments and daub pieces.

Grinding tools along with thermal structures are almost absent from the open area at the East of Building 5 (henceforth Area E5). Instead, Area E5 had yielded several other types of ground stone tools, mostly related to the manufacture and transformation of objects (abraders, pebbles-polishers, hammerstones). It is tempting to interpret those differences as indications of discrete activity areas in the Neolithic Settlement of AVGI I. However, such an interpretation will require further evidence (e.g., the temporal correlation of the deposits) in order to be securely established. However, it seems to be the case that grinding practices at AVGI I are more pronounced at some parts of the open areas, mainly near the houses and in the vicinity of areas with thermal structures. 


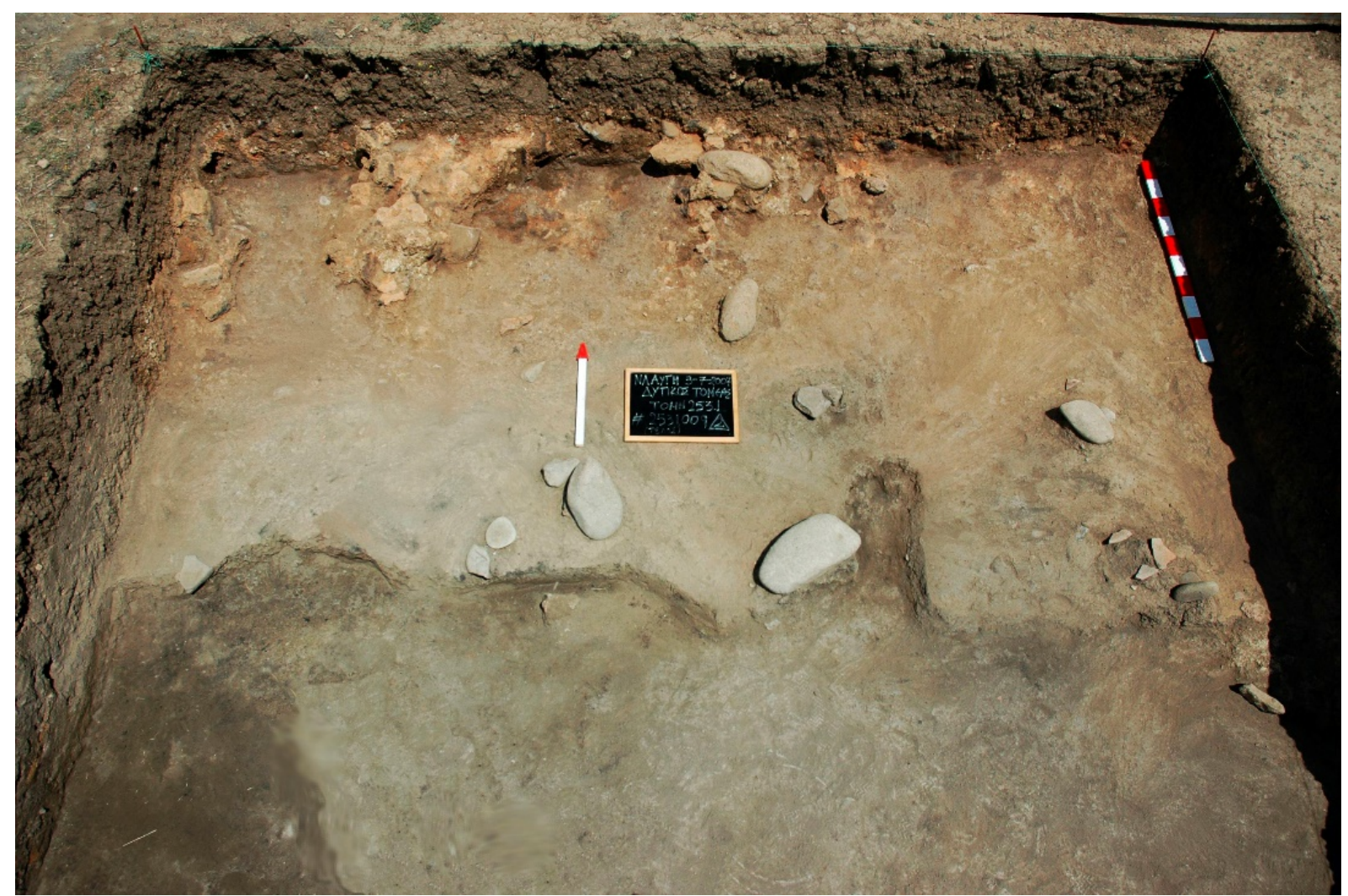

Figure 12. Open area (AVGI I) with in situ grinding tools.

The AVGI I open areas have also yielded modest amounts of debitage from the production sequences of grinding tools. Grinding slab preforms, few unused specimens, possible raw materials and flakes (primary and secondary) indicate that the production of most grinding tools - mainly the ones made out of fine or medium grained sandstones - took place on-site with the by-products of such processes being discarded in the open areas. A group of 15 granite flakes (Figure 13), unearthed in the same layer of a single excavation trench at Area N5 represents a rather unique find, at least for Neolithic Avgi's ground stone assemblage.

All flakes are primary and they seem to derive from the reduction of the same raw material. They were probably produced during the manufacture of a grinding slab or grinder, since in Neolithic Avgi granite rocks were only used for those two tool types. A few debitage pieces from sandstones also came from that deposit, perhaps indicating that this open area at some point might have hosted activities relevant to ground stone production. Intriguingly, that particular layer also gave the most distinct specimens of deliberately broken grinding tools in the whole assemblage (Figure 14). The co-existence of manufacture evidence and also of deliberately destroyed grinding tools could suggest that the same persons were responsible for both making and destroying the grinding tools. In this context, intentional breaking could be seen more as an act of transformation, maybe in order to produce new blanks that will be consumed again as recycled tools, than as a destructive act that aimed on the ritual killing of the grinding tools. 

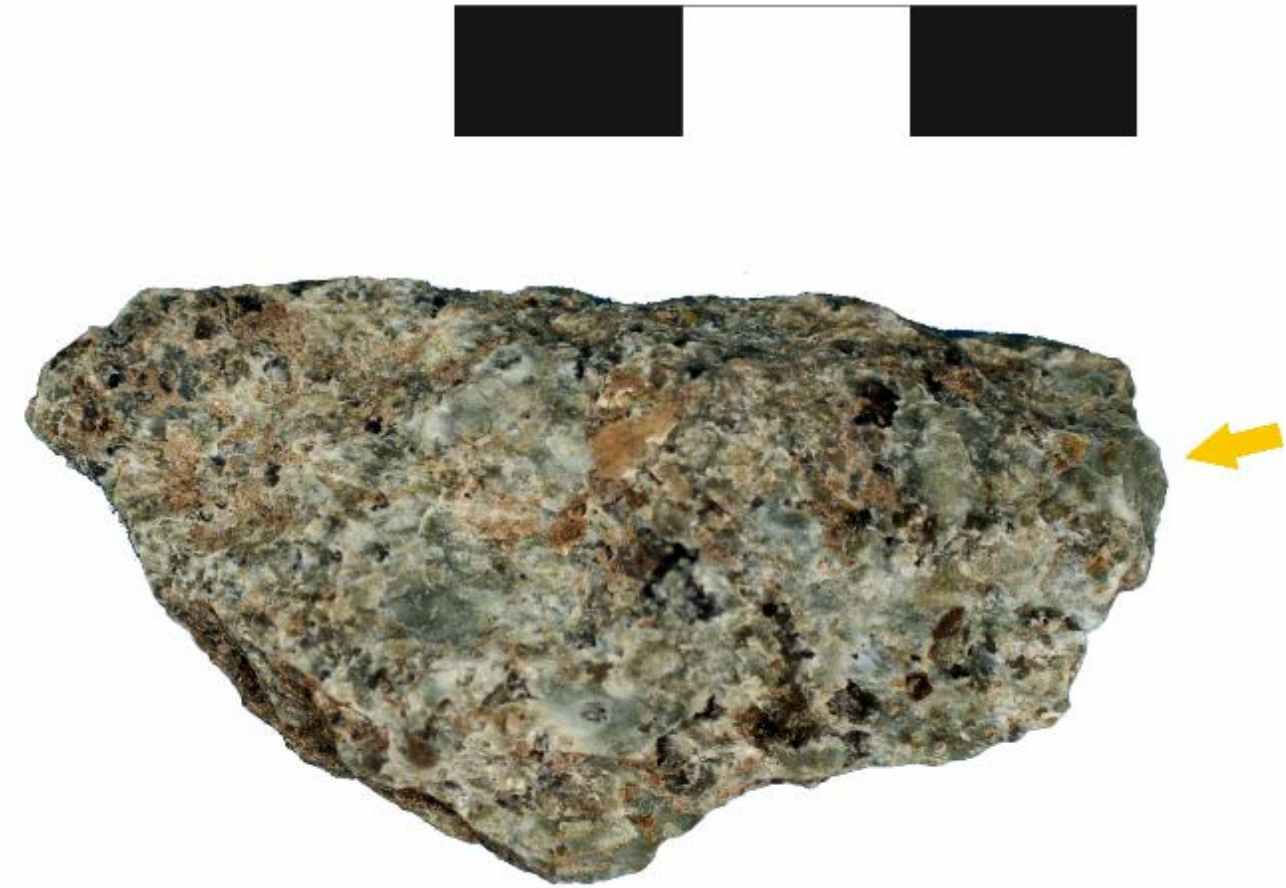

Figure 13. Granite flake from an AVGI I open area (scale in $\mathrm{cm}$ ). The arrow indicates a partially preserved impact platform.
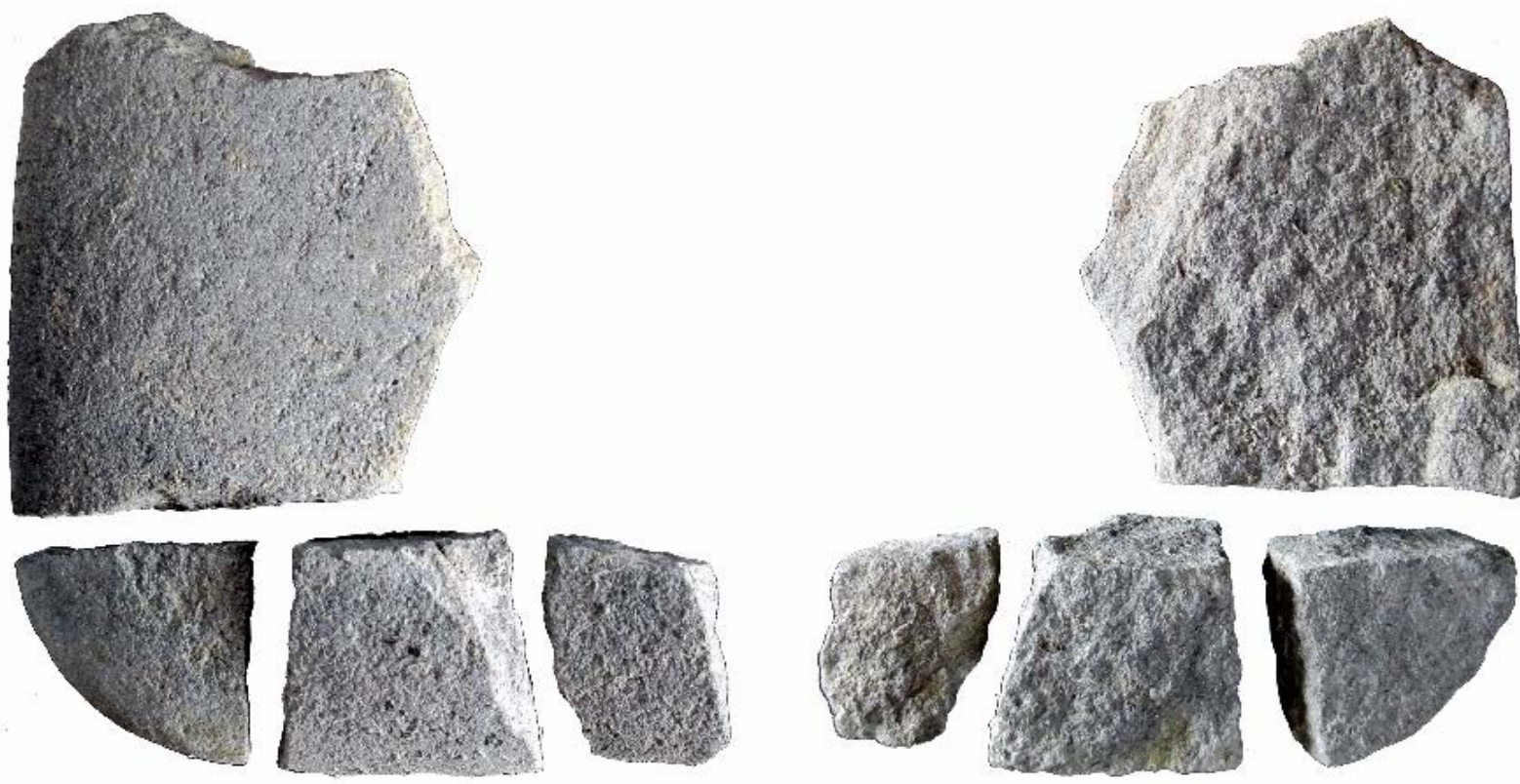

Figure 14. Grinding slab broken through flaking in several pieces from an AVGI I open area. All pieces are refitted (scale in $\mathrm{cm}$ ).

\subsection{AVGI II: Thermal structures}

AVGI II (Late Neolithic I) is more clearly recognized at the western part of the site. It consists of thick, eroded and relatively homogenous deposits that were formed over the remains of AVGI I (Stratouli 2013). No buildings are associated with the AVGI II phase. The invisibility of households, at least as discrete architectural and spatial forms, hinders the comparison with the former occupation phase and raises questions about the character of the 
site. Contrary to the absence of houses, the AVGI II deposits have yielded a considerable number of thermal structures, which were located in situ, thousands of mobile artefacts and large amounts of organic materials, finds that indicate intense human activity at the site (Figure 15). In most cases, these finds seem to represent the remnants of use surfaces that had once belonged to open areas. The thermal structures are again the focal points of those areas, while various domestic practices seem to develop around those structures.

In total 1250 ground stone tools derive from the layers of AVGI II. Of them 249 are grinding tools, mainly handstones or grinders (176), grinding slabs (37) and undetermined grinding tools (36). No significant changes in the grinding equipment are noted in the AVGI II phase. Technological traditions in raw material preferences, manufacture and curation practices, along with the morphometrical attributes of the grinding tools appear to remain stable. However, the use of the grinding equipment becomes more intensive. Tools with two or multiple workfaces occur more frequently, while the number of heavily worn implements slightly increases. The spatial relation between the grinding and cooking practices becomes more distinct in AVGI II, with the grinding tools now located right next to the kitchen facilities. Intriguingly, some of the grinding slabs in those areas still have their active stone component on their surface or right next to it, allowing us to identify actual pairs of grinding tools.

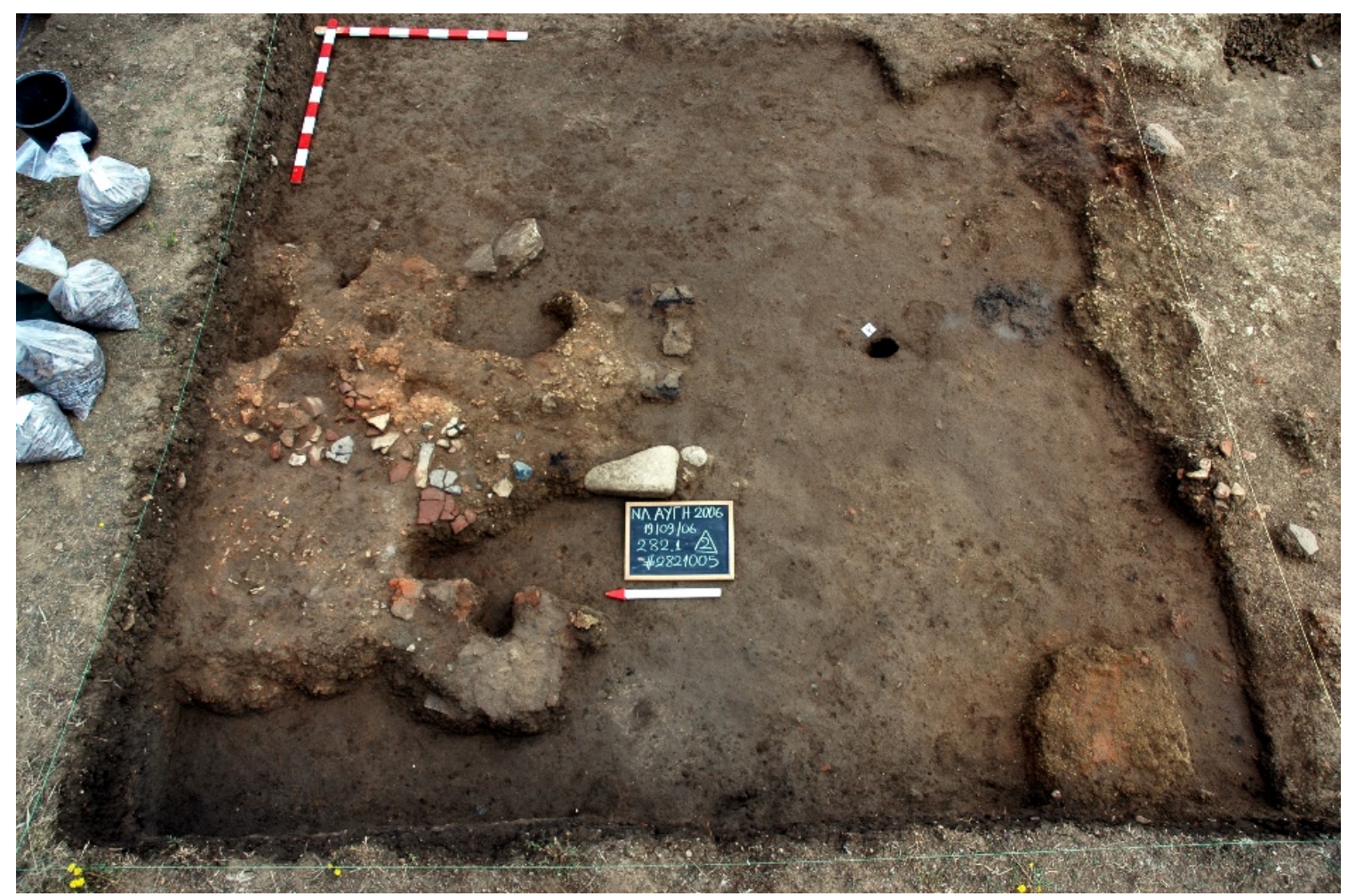

Figure 15. Grinding slabs, tools, pottery and thermal structure remains located in an AVGI II open area.

The grinding tools in these cooking spaces exhibit great variability in their technological attributes, mainly their raw materials, sizes, use wear patterns and workface configurations, pointing to implements that have acted in multiple ways, supporting all kinds of activities, from food preparation to the manufacture of objects and the processing of pigments. These practices had once more occurred 'around the fire' on multipurpose outdoor areas of high interaction and social interplay among the participants. Again, people might have shared both the grinding equipment and the cooking installations on these unbounded, highly visible areas, perhaps in the context of communality and collaboration in daily routine tasks. 
However, as had been suggested by E. Kalogiropoulou (2013: 126) the movement of the grinding tools closer to the thermal structures may reflect a shift towards a more pronounced sense of individuality or ownership (see also Tsoraki 2007). Thus, we can assume that different socialites (collectivity or individuality) could have co-existed in the open areas of AVGI II, and may have been initiated, expressed and manifested around the fire, through the use of the grinding equipment and the cooking facilities.

\subsection{AVGI III: Pits}

AVGI III (Late Neolithic II) is mainly traceable through several cut features, such as foundation ditches, pits and postholes that interrupt the deposits of the previous occupation phases, usually reaching down to the natural bedrock (Stratouli 2005; 2007; 2013). The foundation trenches and postholes indicate the presence of large, rectangular, post-framed buildings. The contents of these buildings along with their whole superstructure and associated open areas have been totally eroded by post depositional factors and modern ploughing (Krahtopoulou 2008), thus making it impossible to investigate the spatial form and organization of domestic practices in this habitation phase. What remains, however, are the rich cultural contents of more than 60 pits, which have been attributed to this phase (Stratouli 2013). The pits display a high degree of variability in their size and shape and great diversity regarding their contents. As discussed elsewhere (Stratouli et al. 2014b), the systematic and interdisciplinary study of the recovered archaeological material from those pits has contributed towards the identification of structured deposits, a selective and socially organized depositional practice with strong symbolic and ideological connotations (Brudenell \& Cooper 2008; Harding 2006; Pollard 2001).

In total, 538 ground stone objects derive from the AVGI III deposits. Grinding tools are represented by 137 artifacts, with 26 grinding slabs, 98 handstones or grinders and 13 grinding tools of undetermined type. Although the technology of grinding implements remains more or less unchanged from the previous occupation phases, the faint appearance of grinding slabs with a concavity in AVGI III may be consistent with a possible shift in grinding practices (e.g., the processing of substances with rotary movements, as indicated by the presence of multidirectional linear traces within the cavities, or the use of the concavities for pounding activities). However, it should be noted that grinding slabs with open workfaces still prevail in the assemblage. In addition, the intensity in the use of the grinding equipment that was observed in the grinding tools of the AVGI II phase continues in AVGI III.

The vast majority of the AVGI III grinding tools came from the interior of pits, while significantly fewer are the tools that were found inside the foundation ditches and the post holes. The filling of the pits was a complex and selective depositional practice that had often occurred in multiple episodes (Stratouli et al. 2014a; see also Hondroyianni-Metoki 2010: 259). Therefore, the contexts and biographies of the grinding tools comprising the contents of each pit, as well as the reasoning behind their selection, are difficult to be sufficiently comprehended. However, the dispositional practices and the contents of some pits can highlight particular ways through which the Neolithic community of AVGI III manipulated and consumed the grinding implements.

The most intriguing example is that of Pit 282302 (Figure 16), where a small grinding slab has been deposited together with more than 70.000 charred seeds of emmer wheat and some building material (Stratouli et al. 2011). The grinding slab is small-sized and bears two opposite, heavily worn workfaces (Figure 17). It was placed at a vertical position on the pit's walls, right next to the burnt seeds. Neither the grinding slab, nor the pit's walls - as the micromorphological analysis points out (Kyrillidou personal communication) - exhibit any traces of burning. Therefore, the seeds must have been burnt elsewhere and prior to their 
deposition into the cutting. The intentional transformation of agricultural products through fire and their deposition into various contexts, such as pits, funerary pots and graves, is a practice well documented in many prehistoric sites in northern Greece and beyond (see Margaritis 2014). The presence of carbonised plants in those contexts has been interpreted as a ritual act, that aimed not at the destruction of the seeds, but at their preservation through their transformation and sacrifice with fire (Margaritis 2014: 281). In the case of Pit 282302 the co-existence of two vital and interconnected elements of the Neolithic life, the grains and the grinding slab, creates a discrete material metaphor with conspicuous and strongly symbolic meaning, expressing perhaps the importance of food processing practices for the economic, social and ideological reproduction of the Neolithic community of AVGI III. Similar contexts with charred agricultural products and grinding tools are known from the Neolithic of northern Europe and from Neolithic Anatolia and have been interpreted as building foundation ritual deposits (Fairbairn et al. 2005; Graefe et al. 2009).

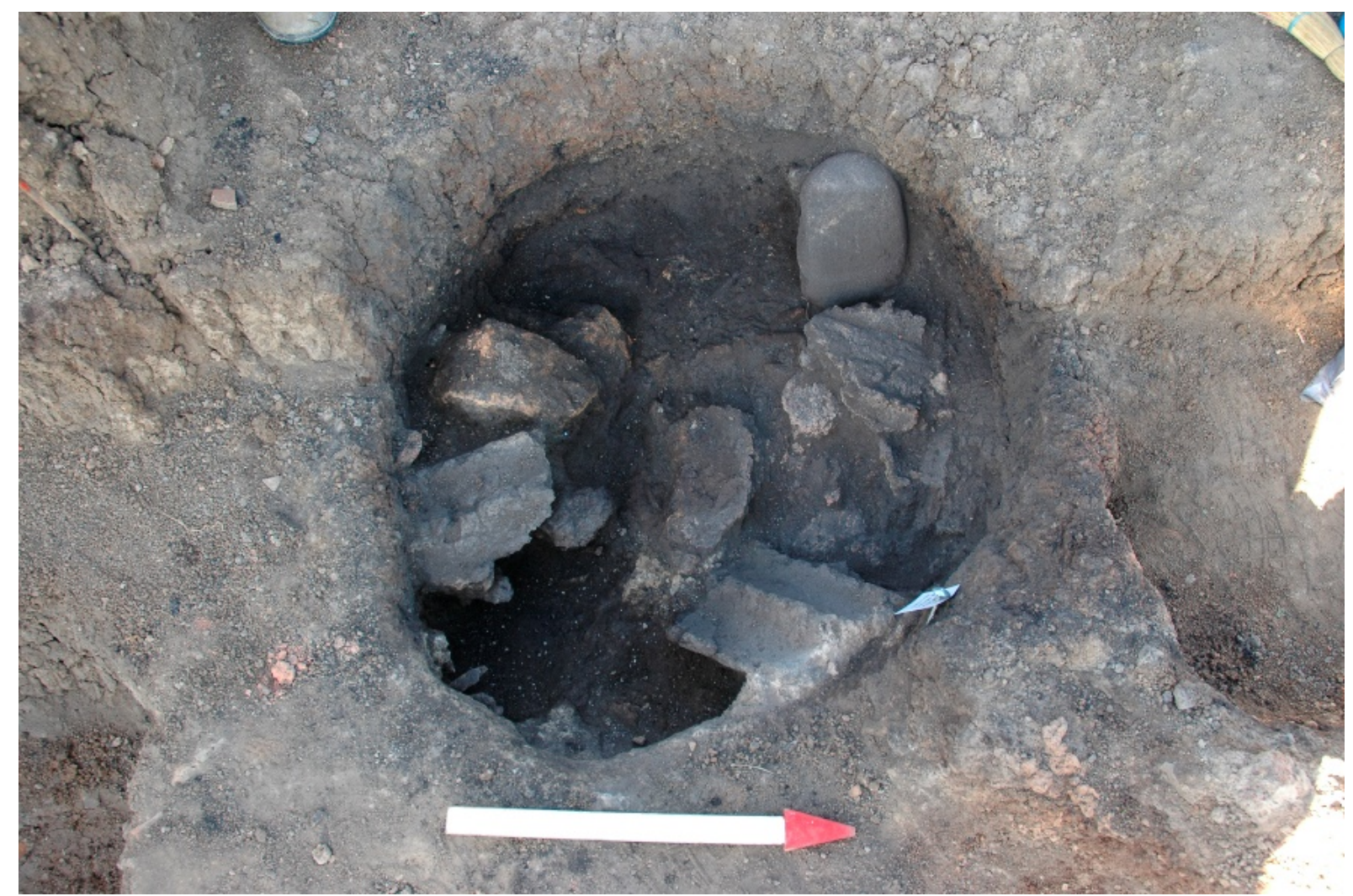

Figure 16. Grinding slab and daub fragment from Pit 282302 (AVGI III).

The contents of other AVGI III pits are significantly different, indicating the variability that characterizes the formation of their fills. Pit 223101, for instance, contained 19 ground stone tools. Of them 17 tools represent grinding slab fragments that were recycled as grooved abraders. Pit 253201 contained mostly disused ground stone artifacts, among them fragments of burnt and destroyed grinders, but no grinding slabs. On the contrary to that, Pit 109401 (Figure 18) had yielded 32 grinding tools, 7 grinding slabs, 24 grinders and 1 undetermined grinding tool. Most grinding tools are intact and represent moderately used implements that had been deposited while they were still fully functional. The grinders from Pit 109401 exhibit great variability in their raw materials, shapes and sizes, but bear similarities in their use wear and workface configuration, pointing to their consumption in the context of similar tasks. As discussed elsewhere (Stratouli et al. 2014b: 282) the grinding tools from Pit 109401 might have been consumed in the context of a single small-scale event of social character 
(e.g., some sort of gathering or feast) and they have been probably deposited inside the pit after the completion of specific practices. This event may have included the communal preparation and consumption of food, as supported by the pottery and other finds from the same pit (e.g., the presence of cooking slabs, animal bones and seeds).
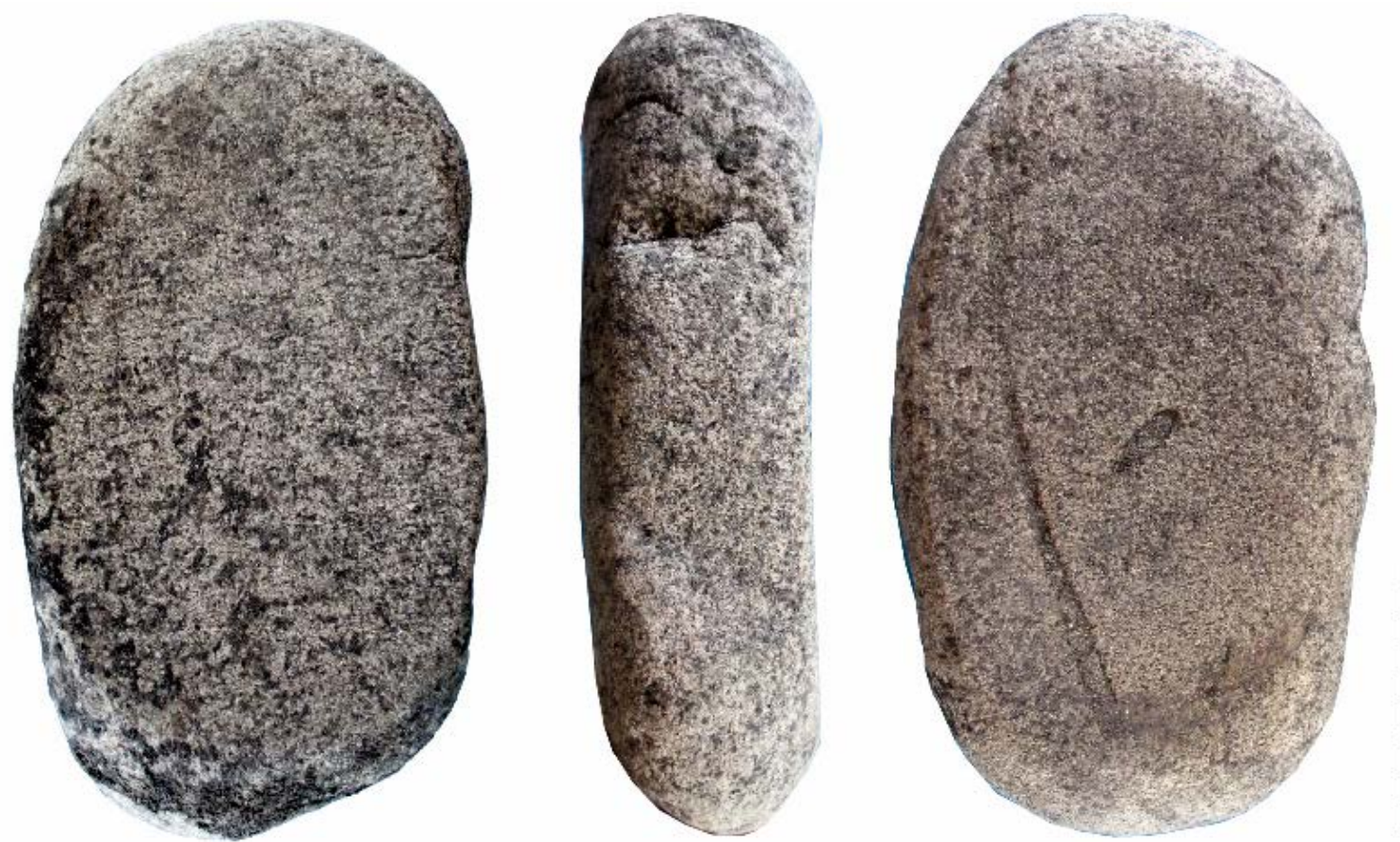

Figure 17. The grinding slab from Pit 282302 (AVGI III). Workfaces and profile (scale in cm).

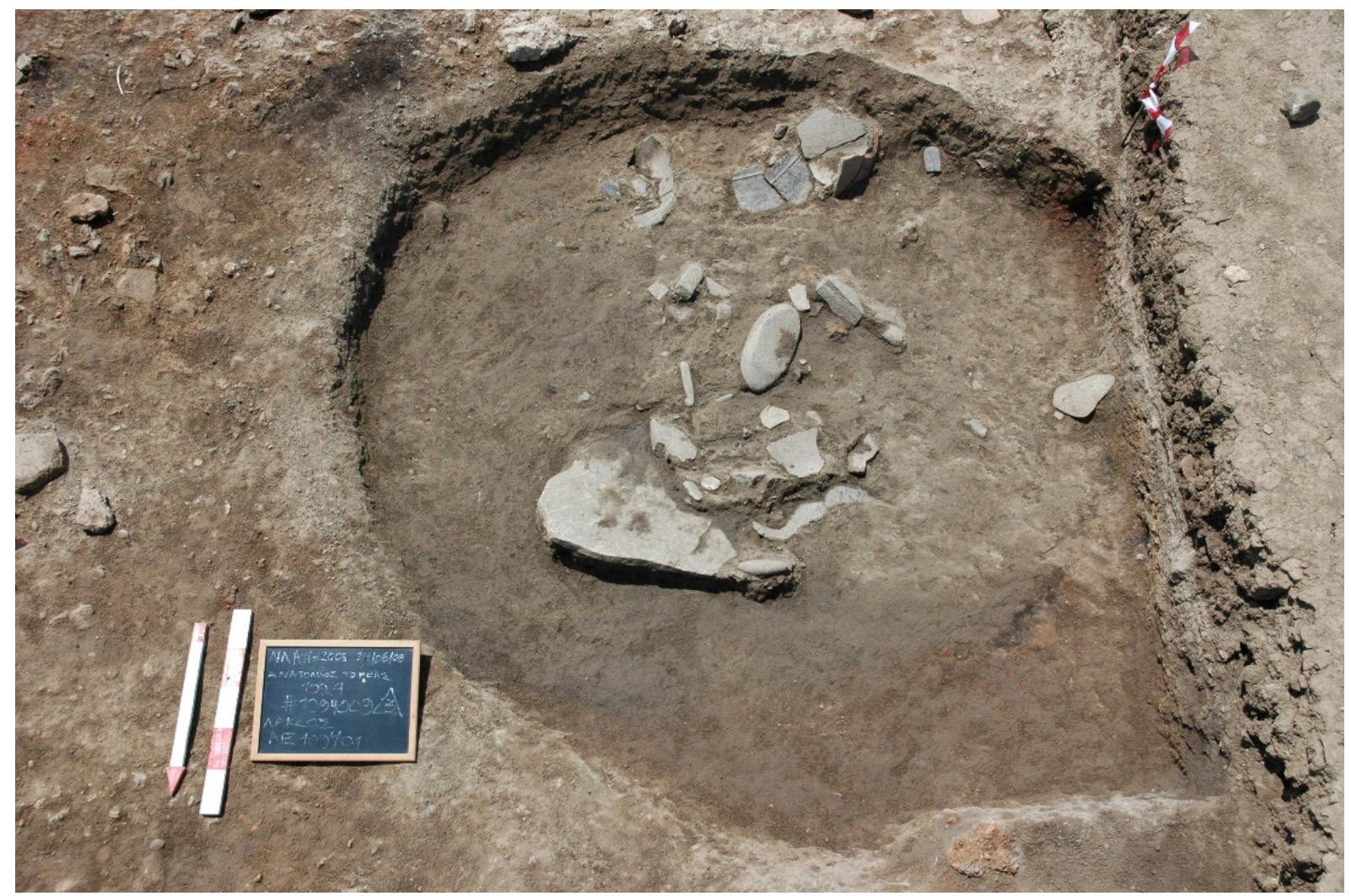

Figure 18. Grinding tools and pottery from Pit 109401 (AVGI III). 


\section{Conclusions}

This paper investigated the contexts of production, consumption and discard of the grinding implements from Middle-Late Neolithic Avgi. By looking at the spatio-temporal distribution of these artifacts, we have tried to approach the multiple ways through which the Neolithic society of Avgi had consumed those technological products within various social occasions, practices and places. During the AVGI I phase grinding tools are encountered both inside the private dwellings, but mostly in the open, communal areas between them. The recurring presence of grinding slabs and grinders inside the houses, but also of other ground stone types (edge tools and percussion tools), points to autonomous social units, each of which had possessed its own 'toolkit' for the processing of some basic daily tasks (Bekiaris 2018: 354-356). Similarities in the technological attributes of the grinding tools indicate that the Neolithic households had access to the same material sources and had shared common technological notions about the manufacture, curation and use of these implements. The coexistence of grinding slabs and agricultural products, some of which at an already processed state, on the house floors could suggest that food preparation activities (grain processing or cooking) were organized by the household and maybe practiced inside the dwellings. However, in the AVGI I phase grinding tools are encountered much more frequently outdoors. Their integrated spatial and technological analysis led to the identification of areas with intact, still active grinding implements that comprise open air loci, where grinding practices took place, but also of refuse areas, that contained broken, destroyed and exhausted grinding tools. Grinding practices occur mostly near the houses and in proximity with open air cooking installations. It seems that both grinding and cooking were not spatially isolated practices. On the contrary, they took place in public view, in communal areas of high social interaction, along with several other daily practices (tool making or discard). The Neolithic households could have shared both the cooking facilities and the grinding equipment of those areas, while multiple social identities would have emerged and negotiated through the coexistence of different crafts and the sharing of daily experiences (see Kalogiropoulou 2013: 131; Stratouli et al. 2011). During the AVGI II phase, grinding practices continue to occur in open areas and in spatial relation with thermal structures. However, there is a notable change in the spatial distribution of the grinding slabs, which are now located right next to the cooking facilities. This change may suggest a shift towards a more pronounced sense of individuality or ownership and could indicate that different forms of socialites (collectivity or individuality) could have manifested in these open areas. AVGI III is a totally different case, since grinding tools are only preserved in the interior of pits. Prior to their deposition these tools may have been consumed within various contexts (inside houses or in communal areas), for several tasks (food preparation, pigment processing or tool making) and within different social events (domestic or individual consumption, or communal events). Through their selective disposition inside the pits, alongside other material elements (pottery, figurines, animal bones, seeds and other tools) that have lived their own biographies, new material entities were assembled. Some of the deposits may have occurred within a ritual context in order to convey symbolic meaning (Pit 282302), while others may have included the remnants of small-scale communal events (Pit 109401). It has been suggested that the burial of ordinary things, such as grinding slabs and grinders, could be interpreted as a commemorative practice that may be tied to specific memories, persons or events in the social life of the Neolithic communities (Graefe et al. 2009; Hamon 2008). 


\section{References}

Adams, J.L. 2008, Beyond the broken. In: New Approaches to Old Stones: Recent Studies of Ground Stone Artifacts (Rowan, Y. \& Ebeling, J., Eds.), Equinox, London: p. 213-229.

Andreou, S., Fotiadis, M. \& Kotsakis, K. 2001, Review of Aegean Prehistory V: the Neolithic and Bronze Age of northern Greece. In: Aegean Prehistory: A Review (Cullen, T., Ed.), American Journal of Archaeology, Suppl. I. Archaeological Institute of America, Boston: p. 259-327. doi:10.2307/507028

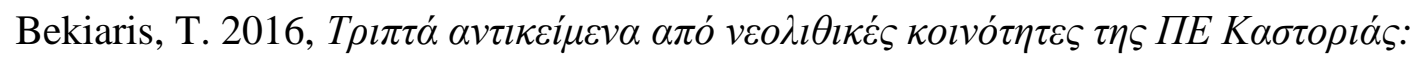

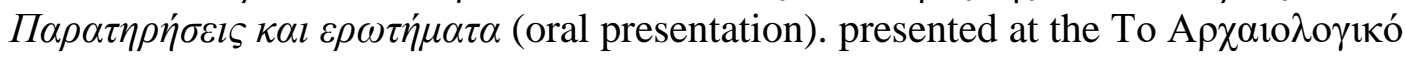

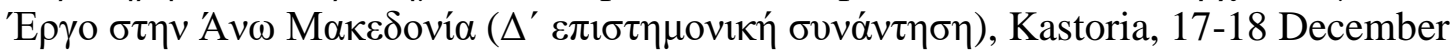
2016. (in Greek) ("Ground stone artifacts from Neolithic communities in the region of Kastoria: Observations and questions”)

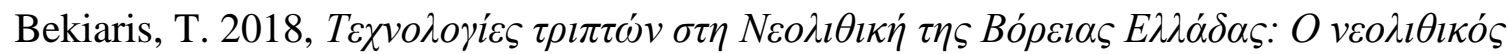

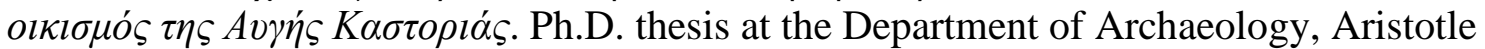
University of Thessaloniki, Thessaloniki, 439 p. (in Greek) ("Ground stone technologies in the Neolithic of northern Greece: the case of Neolithic Avgi, Kastoria”)

Bekiaris, T., Stergiou, Ch. \& Theodoridou, S. 2017, Making choices in a Neolithic landscape: raw materials and ground stone technology in Neolithic Avgi, NW Greece. In: Communities, Landscapes, and Interaction in Neolithic Greece; Proceedings of the International Conference, 29-30 May 2015, Rethymno (Sarris, A., Kalogiropoulou, E., Kalayci, T. \& Karimali, L., Eds.), International Monographs in Prehistory, Archaeological Series Vol. 20. International Monographs in Prehistory, Berghahn Books, New York: p. 415-433. doi:10.2307/j.ctvw049k3.34

Brudenell, M. \& Cooper, A. 2008, Post-middenism: depositional histories on Later Bronze Age settlements at Broom, Bedfordshire. Oxford Journal of Archaeology, 27: 15-36. doi:10.1111/j.1468-0092.2007.00293.x

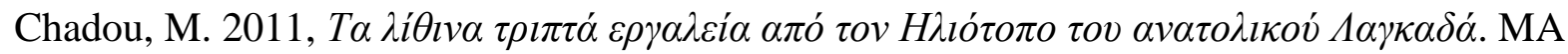
thesis at the Department of Archaeology, Aristotle University of Thessaloniki, Thessaloniki, 156 p. (in Greek) ("Ground stone tools from Iliotopos in Eastern Langadas”)

Chondrou, D., Valamoti, S.M., Procopiou, H. \& Papadopoulou, L. 2018, Grinding cereals and pulses in the Neolithic site of Kleitos. An experimental investigation of microconglomerate grinding equipment, final products and use wear. Journal of Greek Archaeology, 3: 23-45.

Dubreuil, L. 2008, Mortar versus grinding-slabs and the neolithization process in the Near East. In: "Prehistoric Technology" 40 Years Later: Functional Studies and the Russian Legacy (Longo, L. \& Skakun, N., Eds.), Museo Civico di Verona, and Universita degli Studi di Verona, Verona: p. 169-177.

Fairbairn, A., Near, J. \& Martinoli, D. 2005, Macrobotanical investigation of the North, South and KOPAL Area excavations at Çatalhöyük East. In: Inhabiting Çatalhöyük: Reports from the 1995-1999 Seasons (Hodder, I., Ed.), McDonald Institute for Archaeological Research, Cambridge, British Institute for Archaeology at Ankara, London: p. 137-202. doi:10.1017/s0003598x00097015 
Van Gijn, A. 2014, The ritualization of agricultural tools during the Neolithic and the Early Bronze Age. In: Exploring and Explaining Diversity in Agricultural Technology (van Gijn, A., Whittaker, J.C. \& Anderson, P.C., Ed.), Oxbow, Oxford: p. 311-318.

Graefe, J., Hamon, C., Lidström-Holmberg, C., Tsoraki, C. \& Watts, S. 2009, Subsistence, social and ritual practices: quern deposits in the Neolithic societies of Europe. In: $D u$ Matériel au Spirituel. Réalités Archéologiques et Historiques des «Dépôts» de la Préhistoire à nos jours XXIXe Rencontres Internationals d'Archéologie et d'Histoire d’Antibes (Bonnardin, S., Hamon, C., Lauwers, M. \& Quilliec, B., Eds.), Éditions APDCA, Antibes: p. 29-38.

Hamon, C. 2008, The symbolic value of grinding stones hoards: technical properties of Neolithic examples. In: Hoards from the Neolithic to the Metal Ages: Technical and Codified Practices (Hamon, C. \& Quilliec, B., Eds.), British Archaeological Reports, International Series Vol. 1758. Archaeopress, Oxford: p. 19-28.

Harding, J. 2006, Pit-digging, occupation and structured deposition on Rudston World, Eastern Yorkshire. Oxford Journal of Archaeology, 25(2): 109-126. doi:10.1111/j.14680092.2006.00252.x

Hodder, I. 2017, Things and the slow Neolithic: the Middle Eastern transformation. Journal of Archaeological Method and Theory, 25(7555): 155-177. doi:10.1007/s10816-0179336-0

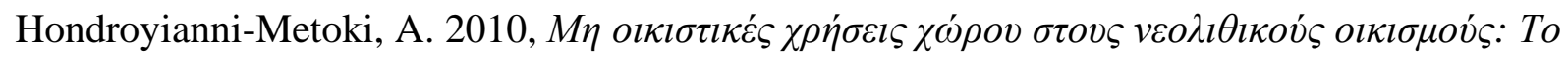

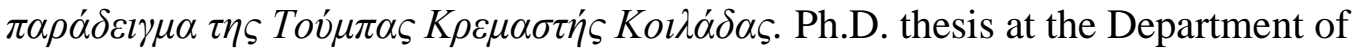
Archaeology, Aristotle University of Thessaloniki, Thessaloniki, 686 p. (in Greek) ("Non domestic use of space in Neolithic settlements: the case of Toumba Kremasti Koilada”)

Kalogiropoulou, E. 2013, Cooking, space and the formation of social identities in Neolithic northern Greece: evidence of thermal structure assemblages from Avgi and Dispilio in Kastoria. Ph.D. thesis at the School of History, Archaeology and Religion, Cardiff University, Cardiff, 279 p.

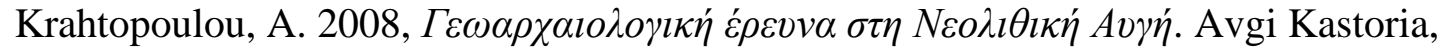
Neolithic Settlement Research Program. (in Greek) ("Geoarchaeological research in Neolithic Avgi”) Retrieved 04/05/2018. URL: http:// http://www.neolithicavgi.gr/?page_id=118\&langswitch_lang=en

Lidström Holmberg, C. 2004, Saddle querns and gendered dynamics of the Early Neolithic in Mid Central Sweden. In: Arrival: Coast to Coast 10 (Knuttson, H., Ed.), Uppsala University, Uppsala: p. 199-231.

Lidström Holmberg, C. 2008, Grinding technologies, social relations and the becoming of the northernmost TRB. In: New Perspectives on Querns in Neolithic Societies (Hamon, C. \& Graefe, J., Eds.), Deutsche Gesellschaft für Ur- und Frühgeschichte, Bonn: p. 69-92.

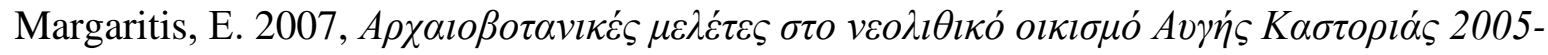
2007. Avgi Kastoria, Neolithic Settlement Research Program. (in Greek) (“Archaeobotanical studies in the Neolithic Settlement of Avgi, Kastoria 2005-2007”) Retrieved 04/05/2018.

URL: http://www.neolithicavgi.gr/?page_id=114\&langswitch_lang=el 
Margaritis, E. 2014, Acts of destruction and acts of preservation: plants in the ritual landscape of Prehistoric Greece. In: PHYSIS. L' environnement naturel et la relation homme milieu dans le monde égéen protohistorique. Actes de la 14e Rencontre Égéenne Internationale, 11-14 Décembre 2012, Institut National d' Histoire de l' Art, Paris (Touchais, G., Laffineur, R., Rougemont, F., Procopiou, H. \& Andreou, S., Eds.), Aegaeum, 37: p. 279-286.

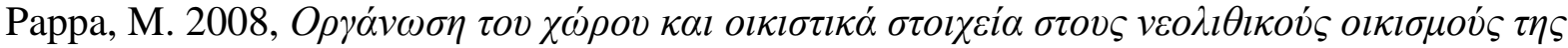

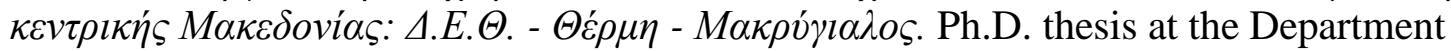
of Archaeology, Aristotle University of Thessaloniki, Thessaloniki, 452 p. (in Greek) ("Organization of space and domestic features in Neolithic settlements from central Macedonia: D.E.TH. - Thermi - Makriyalos”)

Pollard, J. 2001, The aesthetics of depositional practice. World Archaeology, 33(2): 315-333. doi:10.1080/00438240120079316

Rosenberg, D. 2013, Not 'Just another brick in the wall?' The symbolism of ground stone tools in Natufian and Early Neolithic Southern Levantine constructions. Cambridge Archaeological Journal, 23(2): 185-201. doi:10.1017/S095977431300022X

Rowan, Y. \& Ebeling, J. 2008, Introduction: The potential of ground stone studies. In: New Approaches to Old Stones: Recent Studies of Ground Stone Artifacts (Rowan, Y. \& Ebeling, J., Eds.), Equinox, London: p. 1-15.

Searcy, M.T. 2011, The life-giving stone: Ethnoarchaeology of Maya metates. University of Arizona Press, Tucson, 168 p.

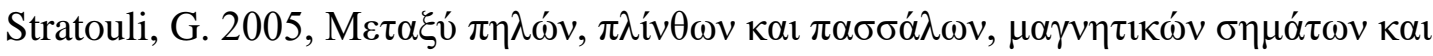

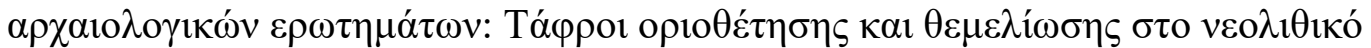

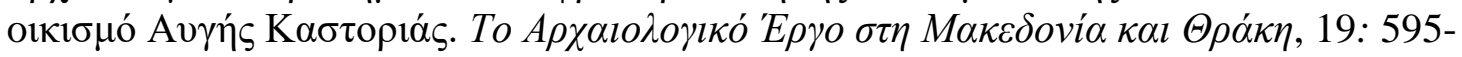
606. (in Greek) ("Amidst clay, bricks and posts, magnetic signals and archaeological questions: boundary and foundation trenches in the Neolithic settlement at Avgi, Kastoria Perfecture”)

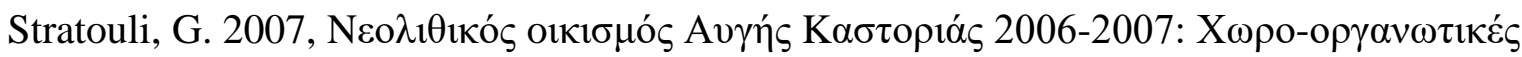

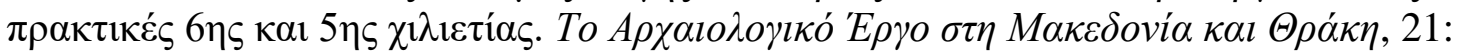
7-14. (in Greek) ("The Neolithic settlement of Avgi, Kastoria (2006-2007): Spatial organization practices during the 6th and 5th millennium”)

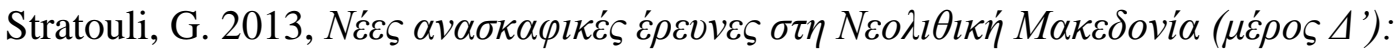

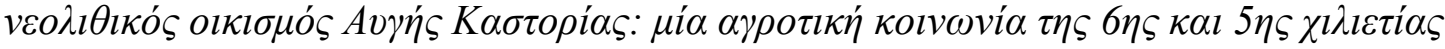
$\sigma \varepsilon \mu \varepsilon \tau \dot{\alpha} \beta \alpha \sigma \eta$. Archaeology \& Arts. (in Greek) ("New excavations in Neolithic Macedonia: Neolithic Avgi, Kastoria: a farming society of the $6^{\text {th }}$ and $5^{\text {th }}$ millennium in transition”) Retrieved 04/05/2018.

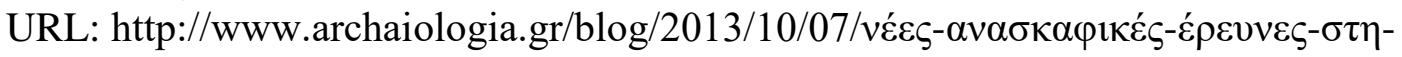
$v \varepsilon 0 \lambda \mathrm{r} \theta \mathrm{t}-4 /$

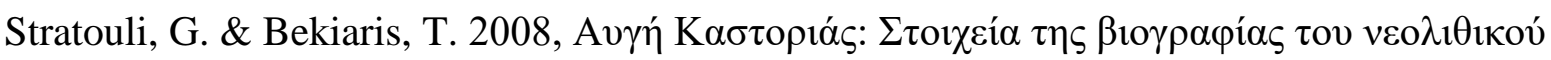

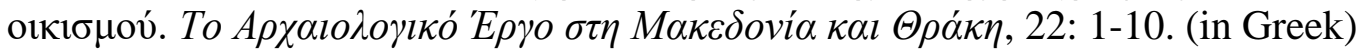
(“Avgi Kastorias: tracing the biography of the Neolithic settlement”)

Stratouli, G., Triantaphyllou, S., Bekiaris, T. \& Katsikaridis, N. 2010, The manipulation of death: A burial area at the Neolithic settlement of Avgi, NW Greece. Documenta Praehistorica, 37: 95-104. doi:10.4312/dp.37.9 
Stratouli, G., Andreasen, N.H., Kalogiropoulou, E., Katsikaridis, N., Kloukinas, D.,

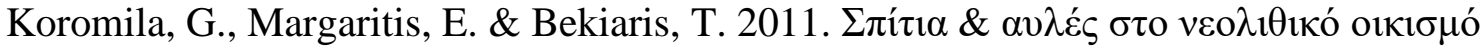

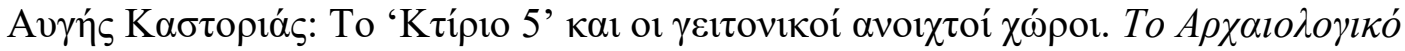

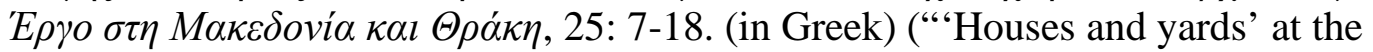
Neolithic settlement of Avgi, Kastoria: Building 5 and the adjacent open areas”)

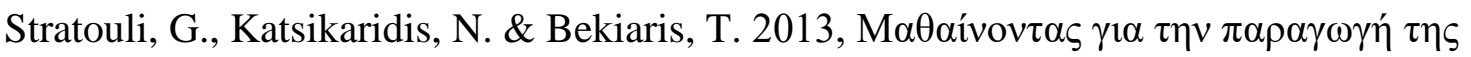

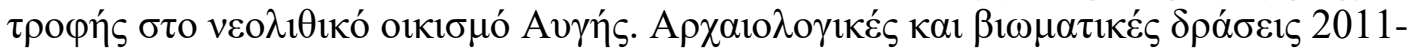

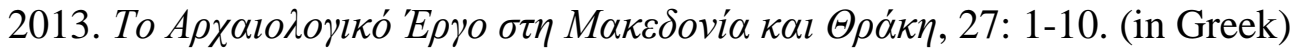
("Learning about food production at the neolithic settlement of Avgi, Kastoria: Archaeological and educational activities 2011-2013”)

Stratouli, G., Bekiaris, T., Katsikaridis, N., Maousidou, E., Petsalnikos, G. \& Tsiola, E.

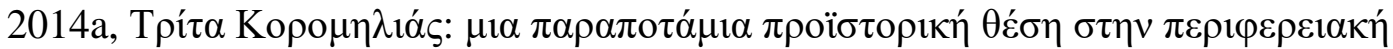

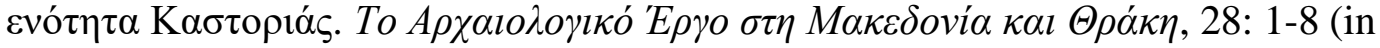
Greek) ("Trita Koromilias: a new prehistoric site in the Perfecture of Kastoria”)

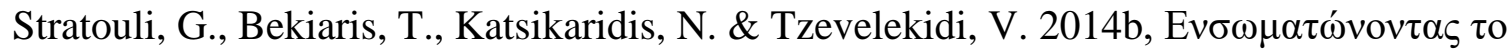

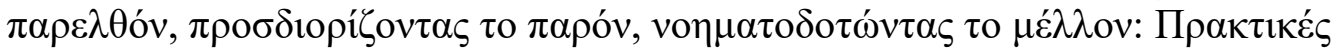

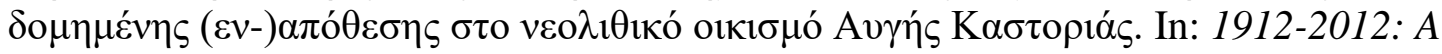
century of research in Prehistoric Macedonia, International conference proceedings, 22-24 November 2012, Archaeological Museum of Thessaloniki (Stefani, E., Merousis, N. \& Dimoula, A., Eds.), Archaeological Museum of Thessaloniki, Thessaloniki: p. 349-357. (in Greek) ("Integrating the past, determining the present, establishing the future: identification and interpretation of structured deposition at the Neolithic settlement of Avgi in Kastoria, northern Greece”)

Stroulia, A. 2010a, Flexible stones: Ground Stone Tools from Franchthi Cave. Indiana University Press, Bloomington, 223 p. doi:10.2307/j.ctv80cdgp

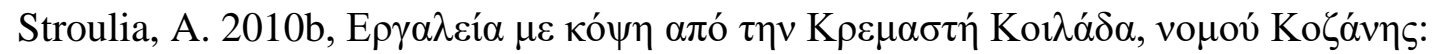

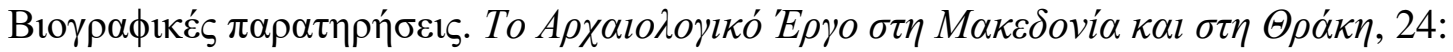
63-71. (in Greek) ("Ground stone edge tools from Kremasti-Kilada, Kozani: Biographical Notes”)

Stroulia, A. 2018, Macrolithics: Ordinary things in an extraordinary place. In: Alepotrypa Cave, Lakonia, Greece (Papathanasiou, A., Galaty, M., Karkanas, P., Parkinson, W. \& Pullen, D., Eds.), Oxbow, London: p. 201-241. doi:10.2307/j.ctvh1dk9q.18

Stroulia, A. \& Chondrou, D. 2013, Destroying the means of production: The case of ground stone tools from Kremasti-Kilada, Greece. In: Destruction: Archaeological, Philological and Historical Perspectives (Driessen, J., Ed.), Presses universitaires de Louvain, Louvain: p. 109-131.

Stroulia, A., Dubreuil, L., Robitaille, J. \& Nelson, K. 2017, Salt, sand, and saddles: exploring an intriguing work face configuration among grinding tools. Ethnoarchaeology, 9(2): 119-145. doi:10.1080/19442890.2017.1364053

Tsoraki, C. 2007, Unravelling ground stone life histories: the spatial organization of stone tools and human activities at LN Makriyalos, Greece. Documenta Praehistorica, 34: 289-297. doi:10.4312/dp.34.22

Tsoraki, C. 2008, Neolithic society in northern Greece: The evidence of ground stone artefacts. Ph.D. thesis at the Department of Archaeology, University of Sheffield, Sheffield, $191 \mathrm{p}$. 
Tsoraki, C. 2011, Disentangling Neolithic networks: Ground stone technology, material engagements and networks of action. In: Tracing Prehistoric Social Networks through Technology: A Diachronic Perspective on the Aegean (Brysbaert, A., Ed.), Routledge, New York and London: p. 12-29.

Wright, K.I. 1994, Ground-stone tools and hunter gatherer subsistence in Southwest Asia: Implications for the transition to farming. American Antiquity, 59(2): 238-263. doi:10.2307/281929

Wright, K.I. 2000, The social origins of cooking and dining in early villages of Western Asia. Proceedings of the Prehistoric Society, 66: 89-121. doi:10.1017/S0079497X0000178X

Wright, K.I. 2014, Domestication and inequality? Households, corporate groups and food processing tools at Neolithic Çatalhöyük. Journal of Anthropological Archaeology, 33: 1-33. doi:10.1016/j.jaa.2013.09.007

Wright, K.I., Tsoraki, C. \& Siddall, R., 2013, The ground stone technologies of Çatalhöyük, 1993-2008. In: Substantive Technologies from Çatalhöyük Reports from the 2000-2008 Seasons (Hodder, I., Ed.), Çatalhöyük Research Project Series, Vol. 9. Monographs of the Cotsen Institute of Archaeology, University of California at Los Angeles: p. 357408.

Ziota, Ch. 2014, O oıkı

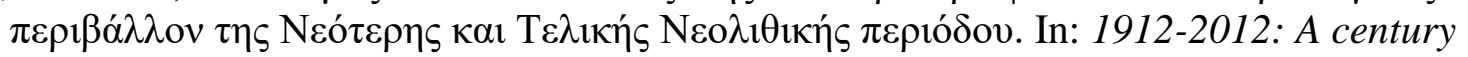
of research in Prehistoric Macedonia, International conference proceedings, 22-24 November 2012, Archaeological Museum of Thessaloniki (Stefani, E., Merousis, N. \& Dimoula, A., Eds.), Archaeological Museum of Thessaloniki, Thessaloniki: p. 323-336. (in Greek) ("The settlement of Kleitos Kozanis in its wider natural and anthropogenic environment during the Late and Final Neolithic periods”) 